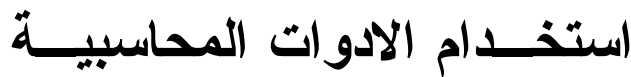 في تقييم أداء المستثفيات (")
}
طه احمد حسن أرديني
مدرس مساعد - قسم المحأسبة ألادية
كلية الادارة والاقتصاد -جامعة الموصل
Ardiny 2003@yahoo.com

\author{
مقداد احمد الجليلي \\ التتاذ مساعد - قسم المحاسية الإلية \\ كلية الادارة و الاقتصاد -جامعة الموصل \\ Mqjalili@yahoo.com
}

المستخلص

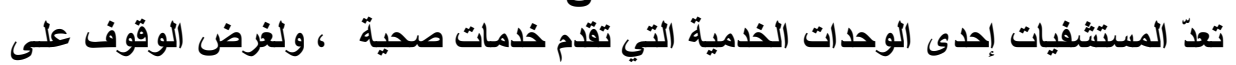

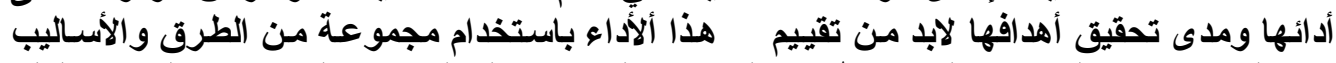

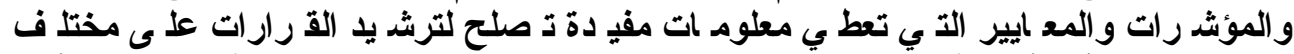

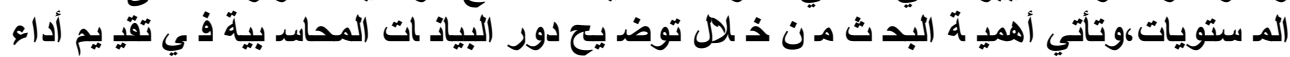

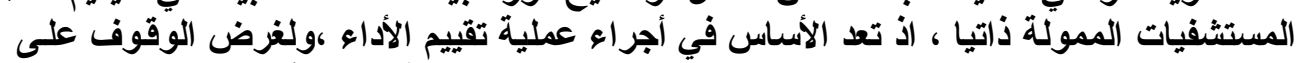

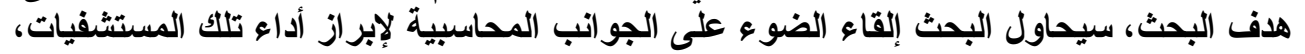

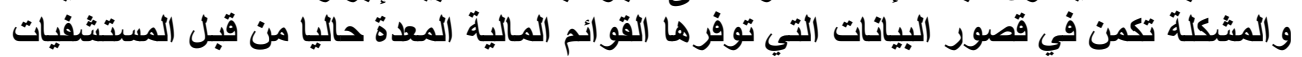

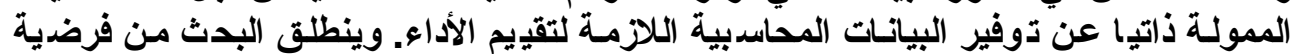

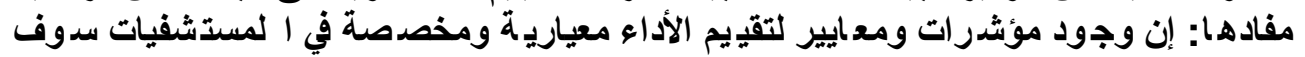

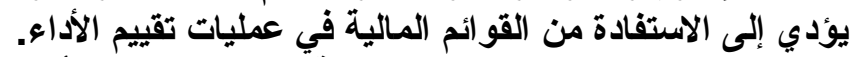

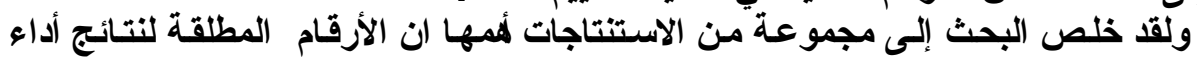

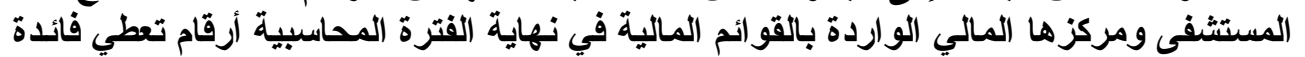

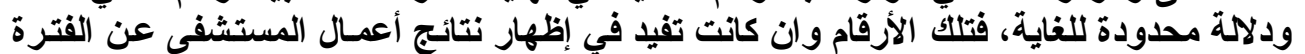

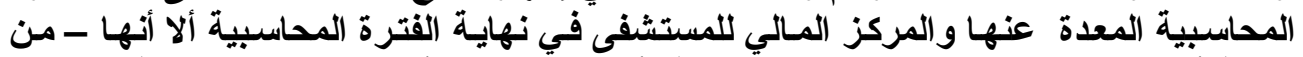

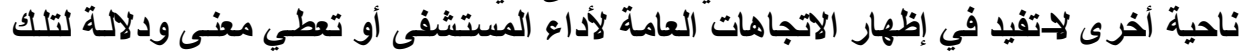

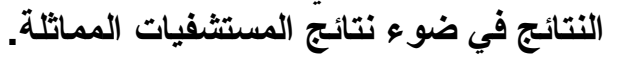

(*) البحث مستل من رسالة الماجستير الموسومة "تقييم الأداء باستخدام البيانات المحاسبية للرقابــة

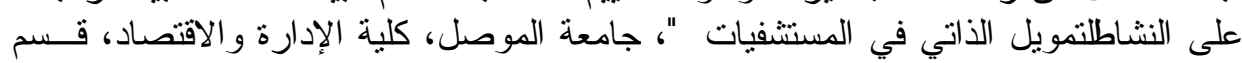

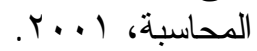

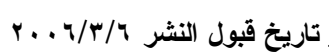
تاريخ التسلم • r/ r/ه . . 


\title{
THE USE OF ACCOUNTANCY TOOLS IN EVALUATING THE HOSPITAL PERFORMANCE
}

\author{
Moqdad A. Al - Jalili \\ Assistant Professor \\ Collage of Administration and Economics \\ University of Mosul
}

\author{
Taha A. Ardiny \\ Assistant Lecturer \\ Collage of Administration and Economics \\ University of Mosul
}

\begin{abstract}
Hospitals are considered to be one of the facilities that offer health services. To find out their performance and the extent to which accomplish the goals, their performance should be evaluated using several techniques, methods, parameters and standards that may offer useful information which helps to make good decisions on various levels. The importance of the current research is manifested through clarifying the accounting data role in assessing the self - financed hospitals that are the basis of evaluating performance. In order to obtain that goal, the present research highlights the accounting aspects to show the performance of hospitals. The problem lies in the shortage of data provided by the financial lists of the self - financed hospitals. The research draws upon the hypothesis that there are several indicators and standards to evaluate the performance. They will lead to make use of the financial lists used in evaluating the performance in general.

The research concluded a group of results. The most important of them are that the absolute numbers of the hospital performance results and their financial status in the financial lists at the end of the accounting period are numbers that give a limited significance and benefit. These numbers -although they show the results of the hospital activity of the accounting period and show the financial status of the hospital at the end of the accounting period - are not useful in showing the general tendencies of the hospital performance and showed no significant results in lights of the similar hospitals. To evaluate the hospital performance and to accomplish the optimum benefit from the numbers in the financial lists of the hospital, it is possibly use a technique called the financial analysis which uses the financial rates.
\end{abstract}

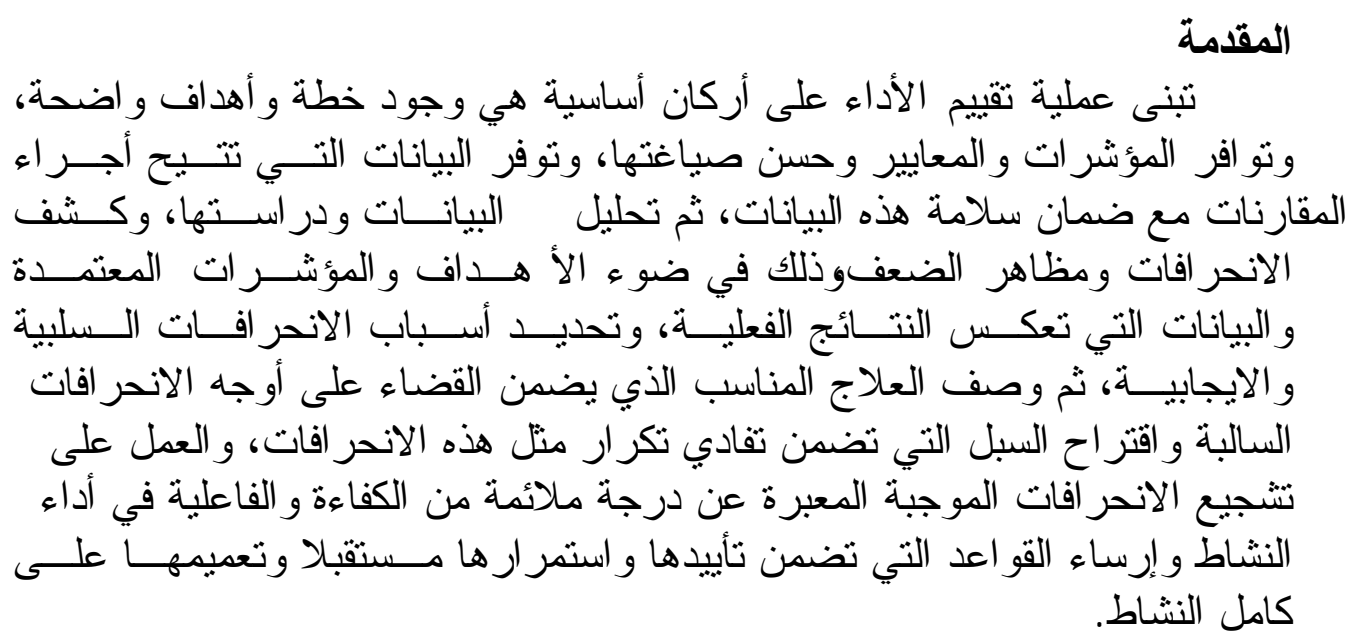




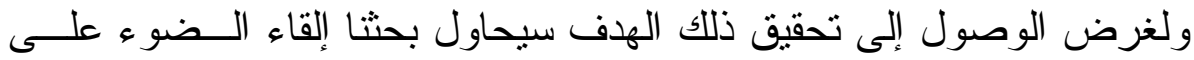

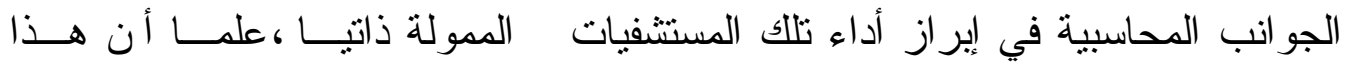

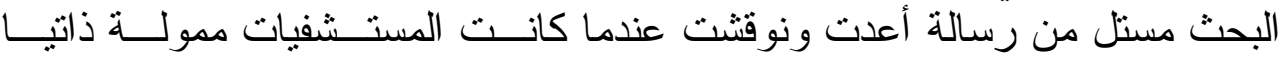

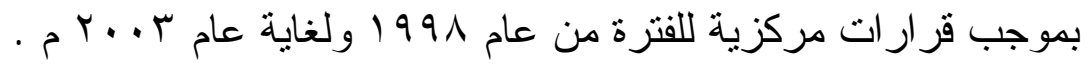

مشكلة البحث

قصور القو ائم المالية المعدة حاليا من قبل المستثفيات الممولة ذاتيا عن توفير البيانات المحاسبية اللازمة لتقييم الأداء.

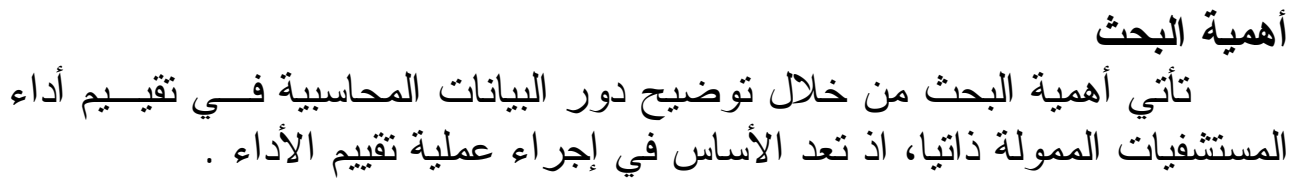

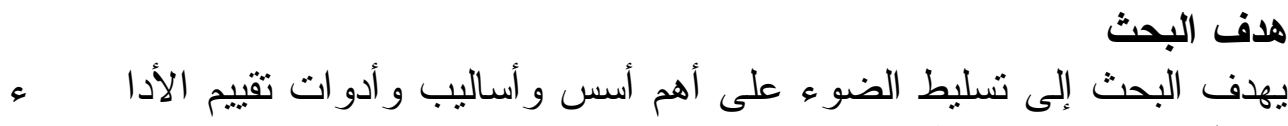

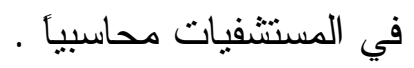

فرضية البحث

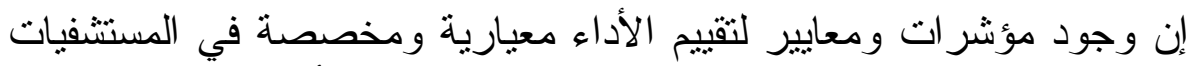

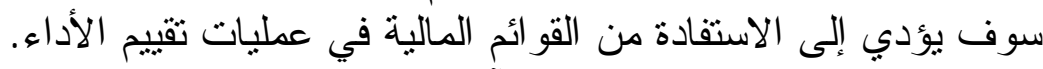

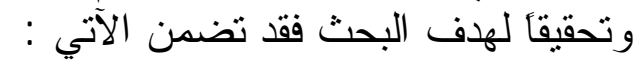

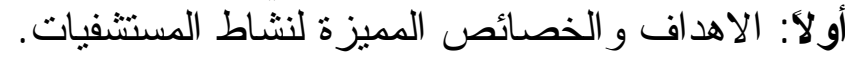
ثانياً: خطوات الات و أسس تقييم الأداء في العيزة الدستثفيات. ثالثا: أساليب تقيبيم الأداء في المستشفيات.

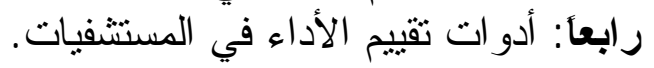

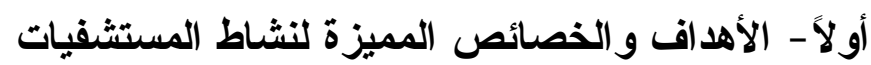

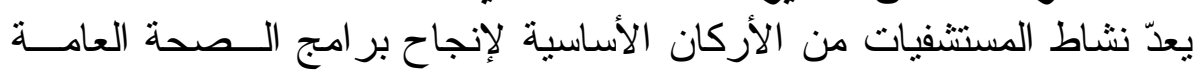

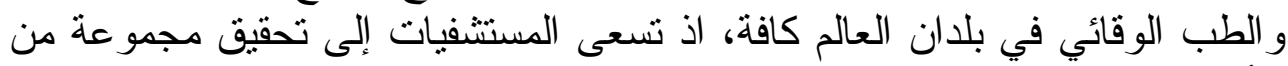

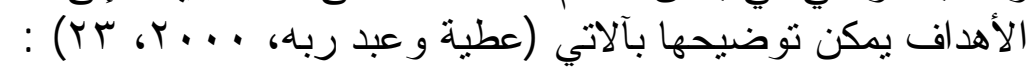

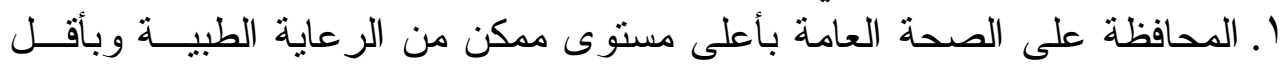

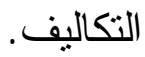

r. تحقيق مستوى مرض من الربحية - في حالة تقديم الخدمات العلاجية بأجر .

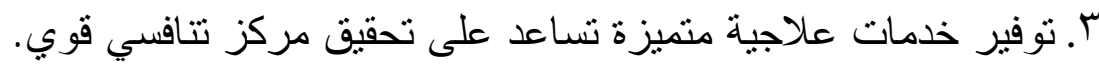

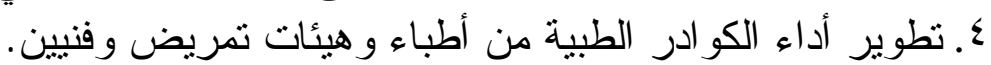
وتتحقق هذه الأهداف في المستشفيات من خلال: 


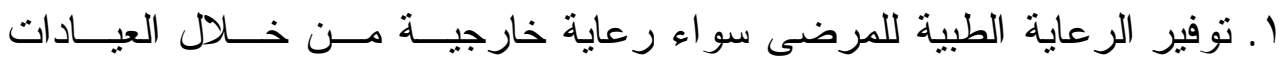

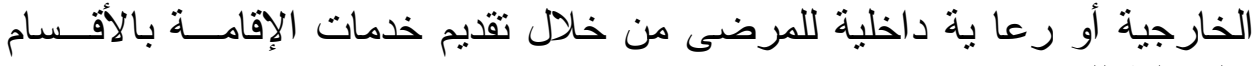

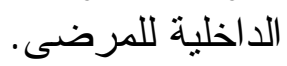

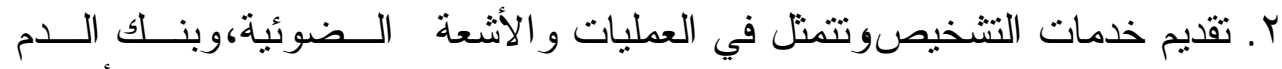
ووظائف التتفس، و الميكروسكوب الإلكتروني، ووحدة المناعة، وزرع الأعلى الأعضاء

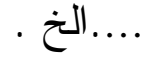

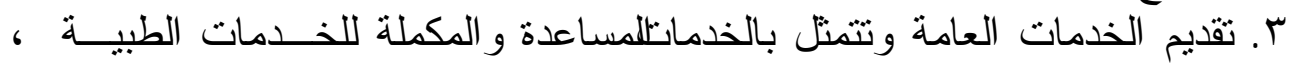

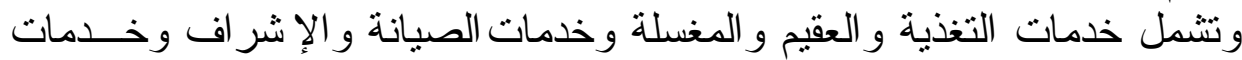
الإقامة.

ع. الوقاية من الأمر اض و العمل على تحسين الصحة العامة . 0. التعليم و التدريب و البح البحوث .

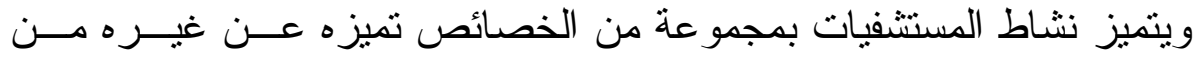

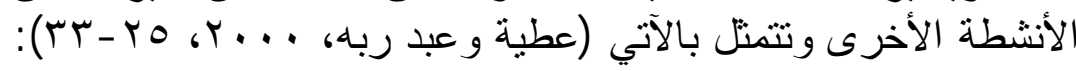

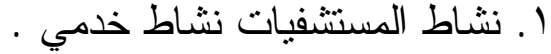

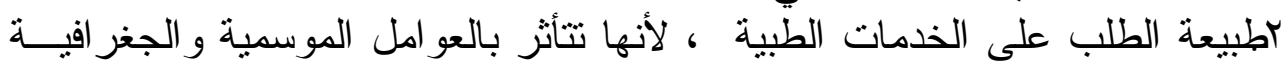
و السياسية و الاجتماعية.

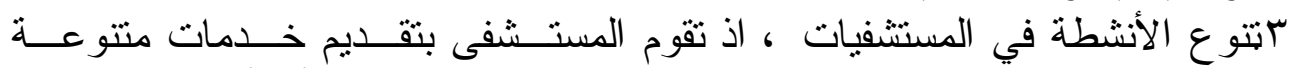

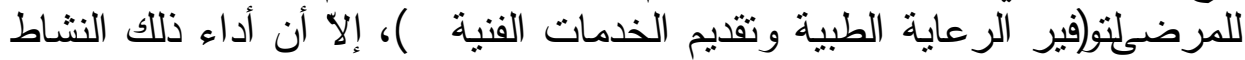

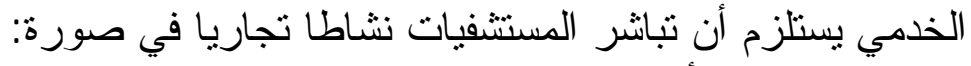

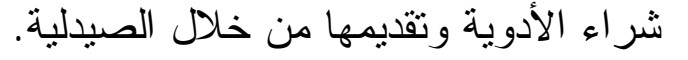

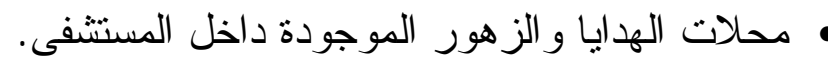

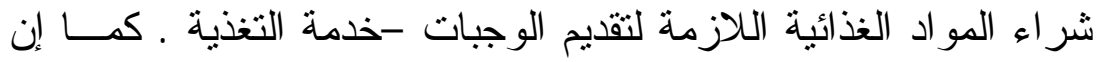

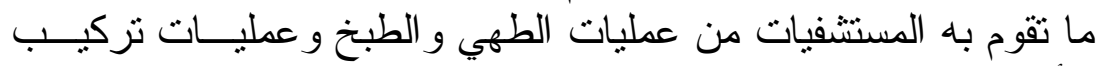

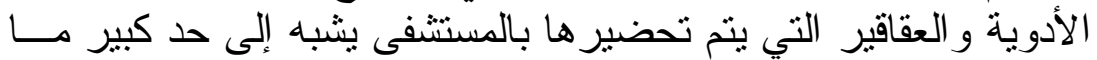

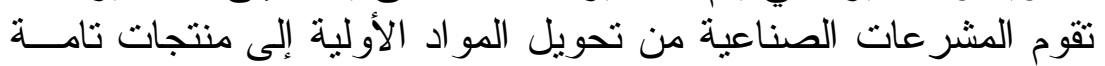

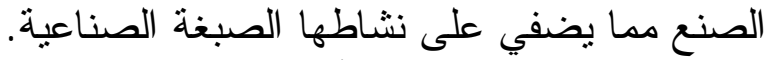
ء. تقسيم نشاط المستشفيات إلى مر اكز (أقسام) .

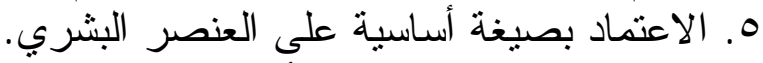

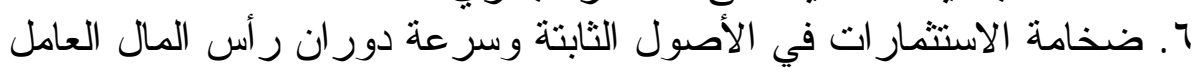

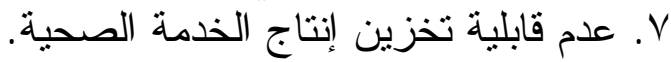

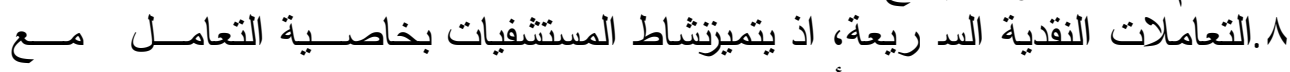

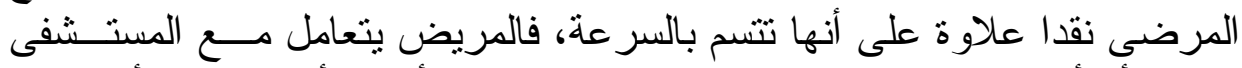

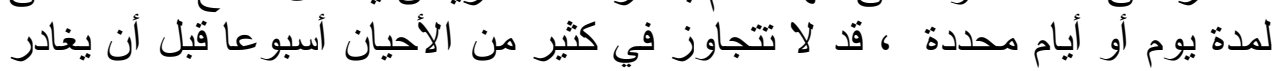
المسنتفى ويسدد حسابه. هالإحلال و التجديد حيث يتميز نشاط المستش فيات بخاصية نظام الإحلال و التجديد

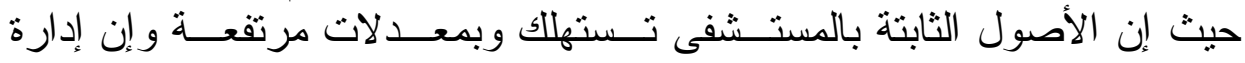


المستشفى ترغب في إن تكون هذه الأصول في حالــة جيــدة بــصفة مسـستمرة

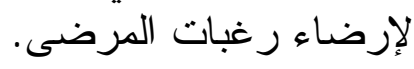
• 1 ـ صعوبة قياس المخرجات وتقات وتييمها:

يتميز نشاط المستشفيات بخاصية صعوبة وبهية قياس المخرجات وتقييمها، اذ إنه:

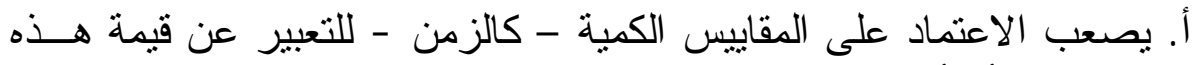

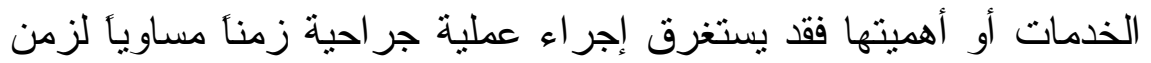
إجر اء فحص طبي على أحد المرضى مع اختلاف أهمية و إيراد كل مــن أهن المريضين.

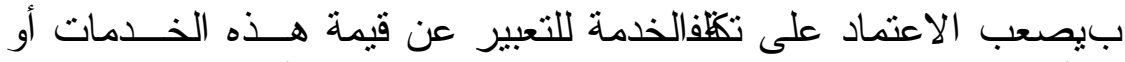

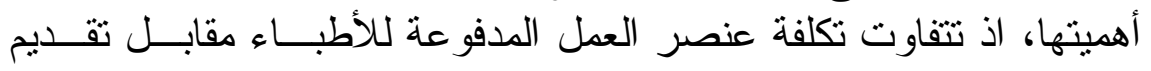

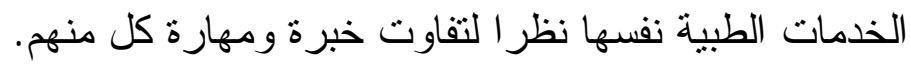

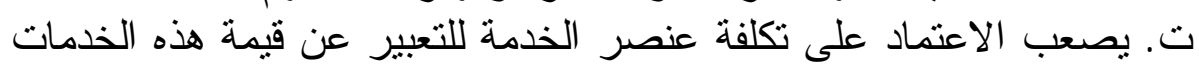

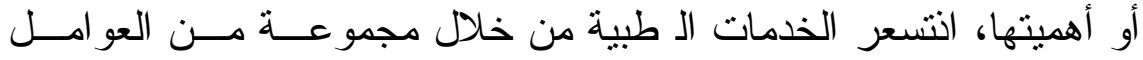

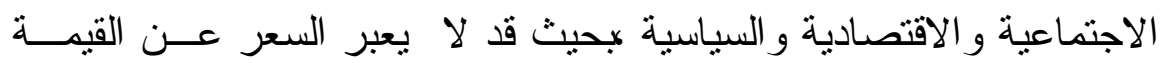
الاقتصادية الحقيقية للخدمة.

\section{ثانياً - خطوات تقييم الأداء في المستشفيات وأسسها}

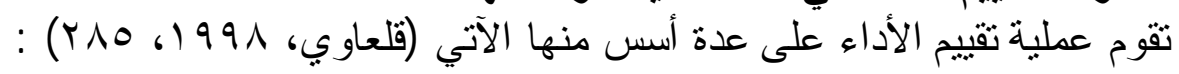

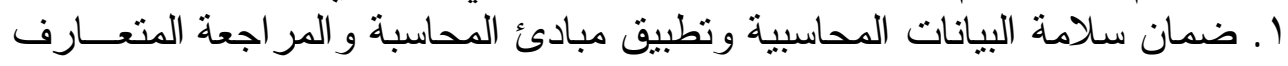
عليها في إعداد تلك البيانات. r. الثبات على إتباع الأساليب المحاسبية و الإجر اءات خلاتل فتــرة المقارنـــة التــي يشملها التقبيم.

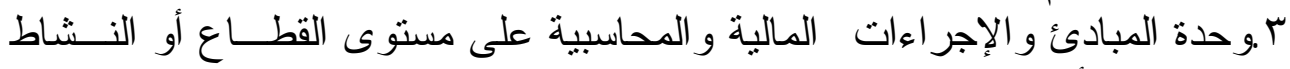

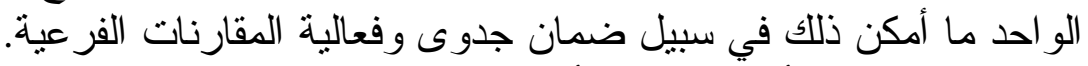

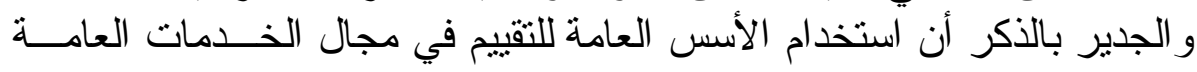

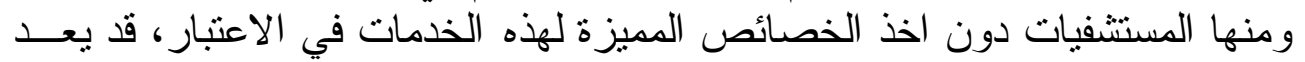

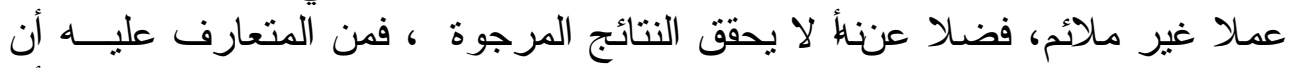

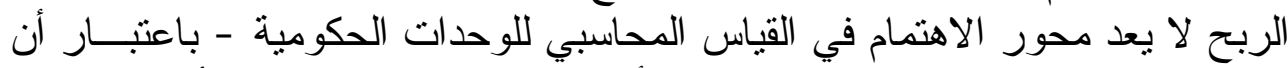

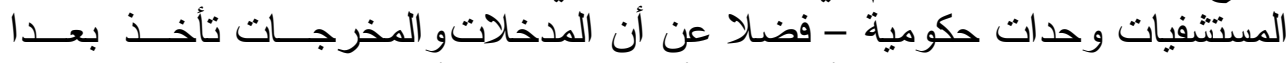

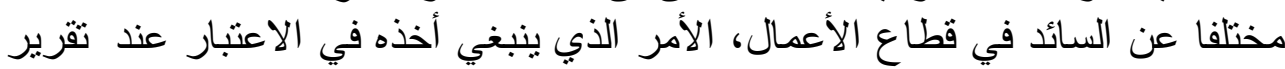

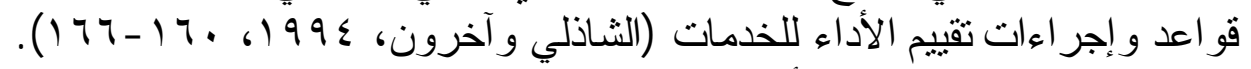

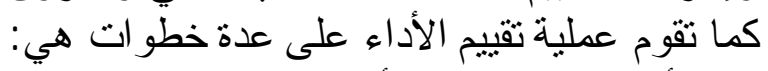

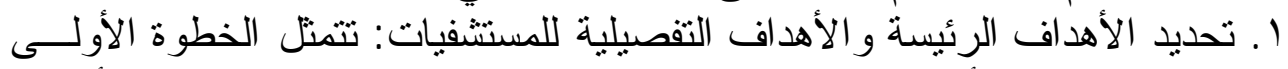

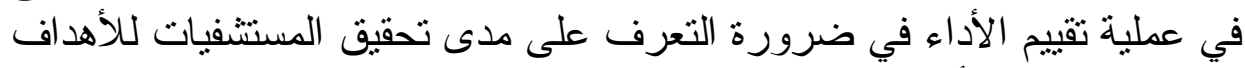

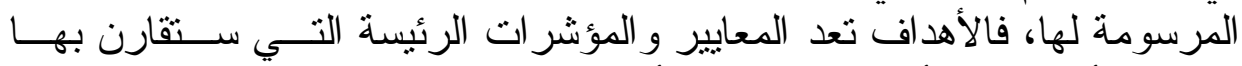

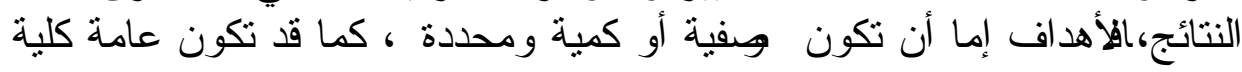




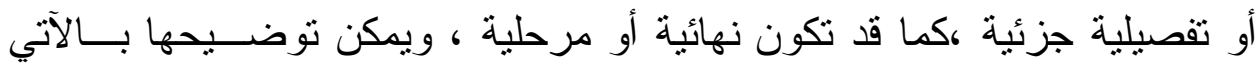

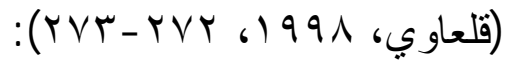

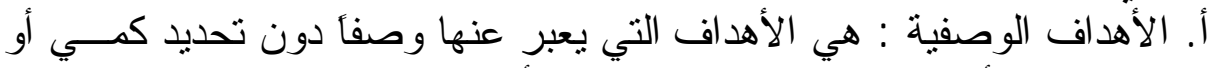

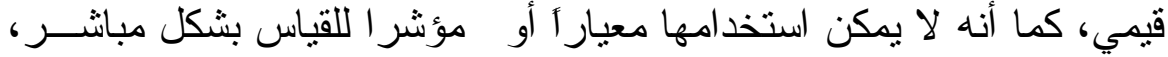

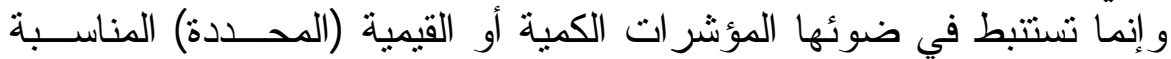

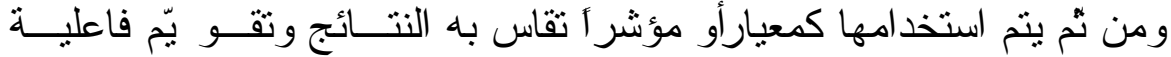

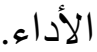

ب. الأهداف العامة او الكلية و الأهداف الجزئية التقصيلية: بقصد بالهدف العام

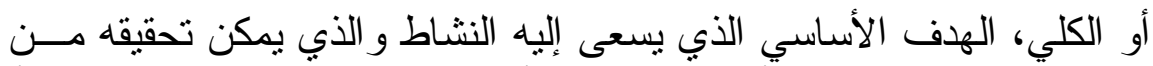
خلال تحقيق مجموعة من الأهداف الجزئية أو التقصيلية ، فالهدف العـام أو أون الكلي يعد محصلة مجمو عة من الأهداف الجزئية أو التقيلة التصيلية.

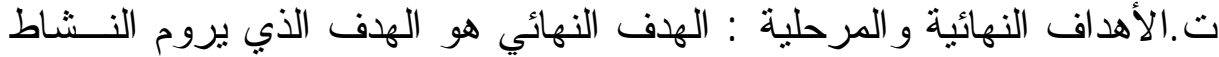

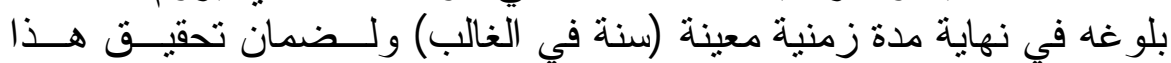

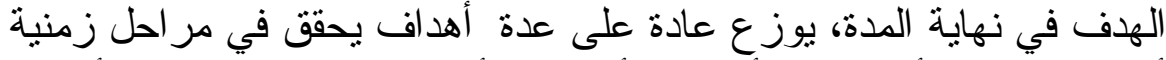

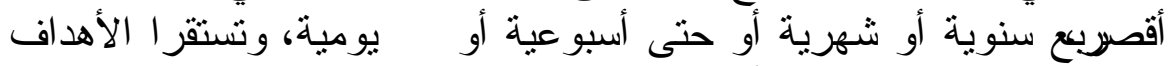

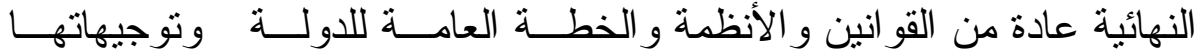

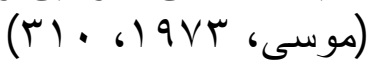
r. تحديد الخطط التقصيلية لإنجاز الأعمال: بعد أن يتم تحديد الأهــــاف، يتطلــب

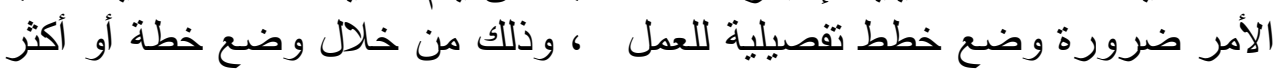

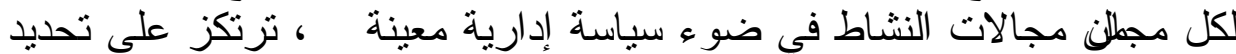

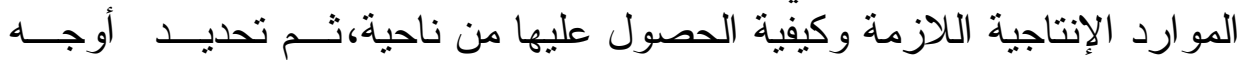
استخدام تلكك الموارد من ناحية أخرى بفرض تحقيق الأهداف المحددة (جـــواد،

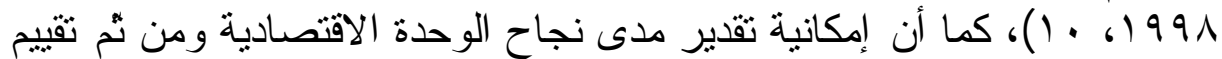

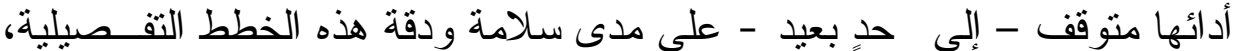

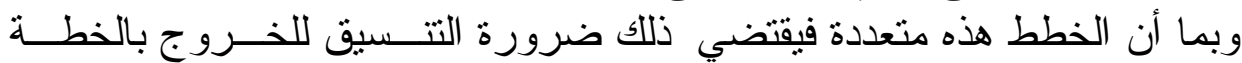

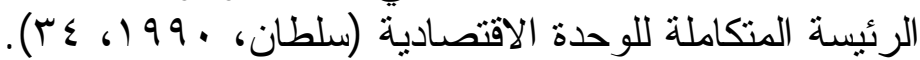

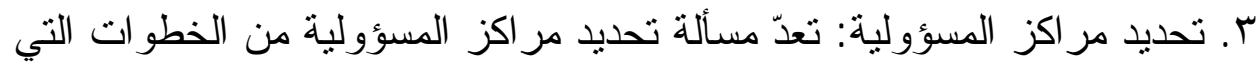

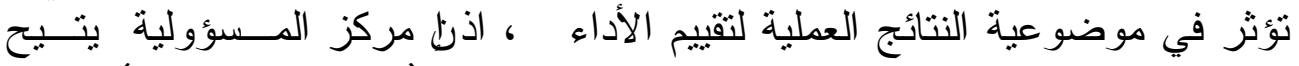

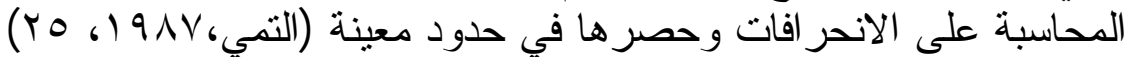

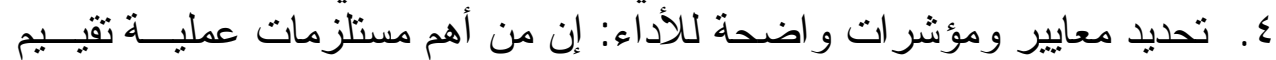

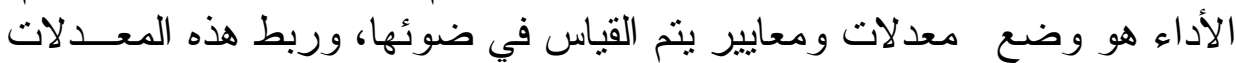

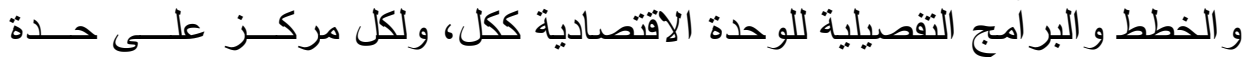

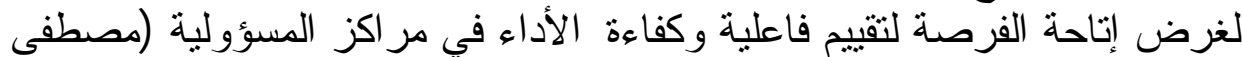

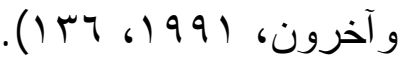

○ـ تحديد الجهة المسؤولة عن تقييم الأداء: من الطبيعي أن فاعلية تتفيذ عملية تقييم الأداء تتطلب ضرورة وجود جهاز يختص بعملية المتابعة و الرقابة علــى الأداء 
الفعلي، ومما لاشك فيه أن فاعلية أبي جهاز يتم إنشاؤه لغرض تقييم الأداء يتوقف

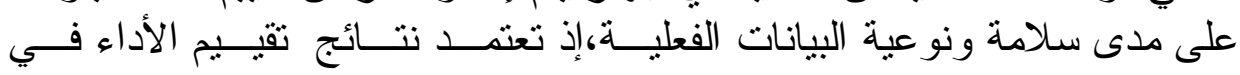

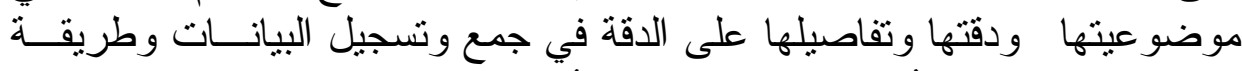

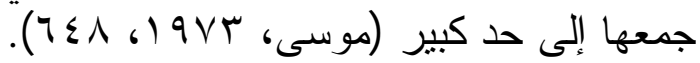

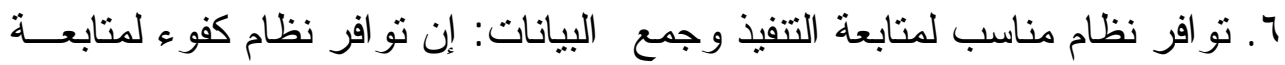

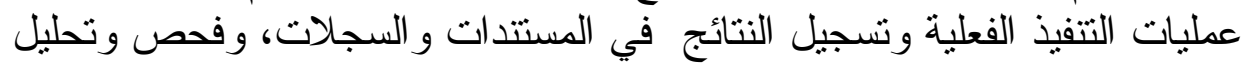

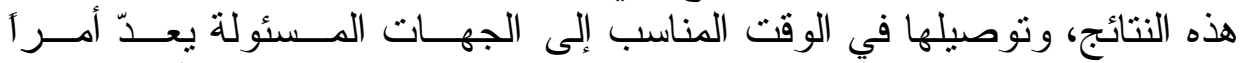

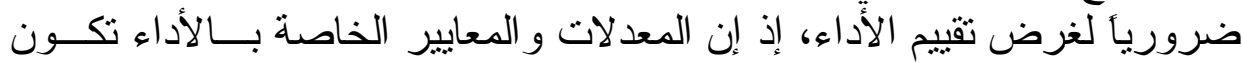

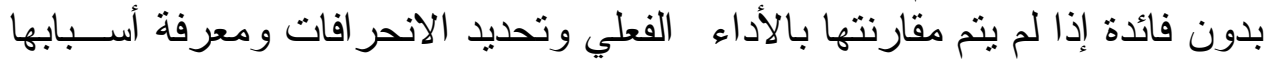

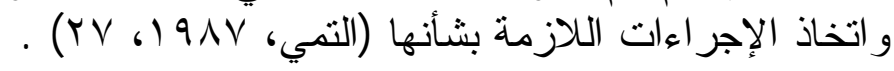

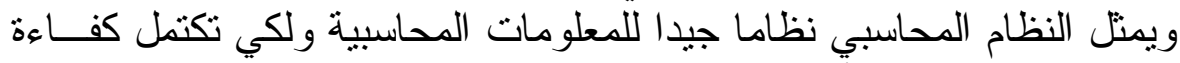

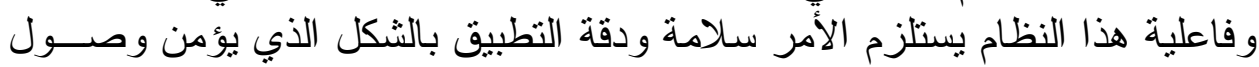

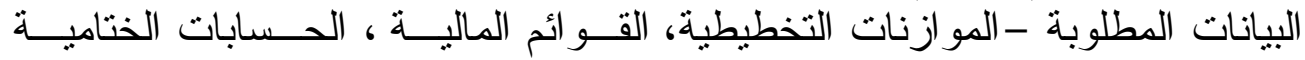

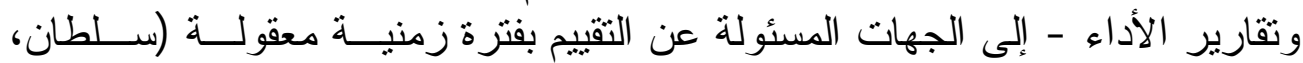
.) (10.) ( )

ثالثاً - أساليب تقييم الأداء في المستشفيات

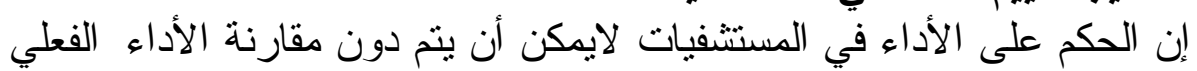

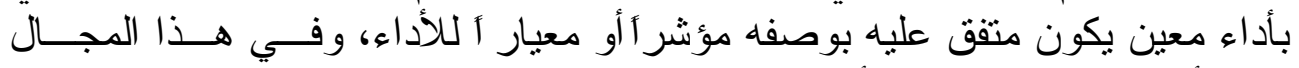

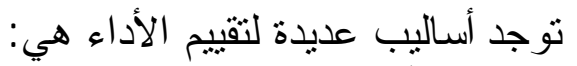
ا ـ مقارنة بيانات الأداء الفعلي للوحدة الخدمية مع الأداء الفعلي للفترة أو الفترات السابقة

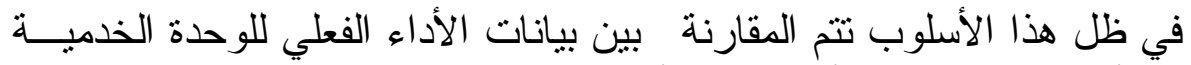

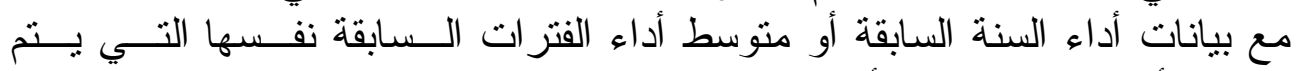

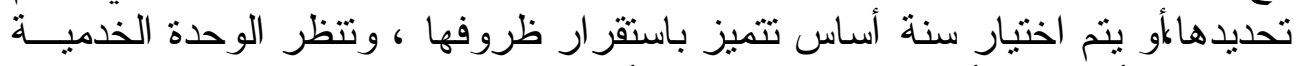

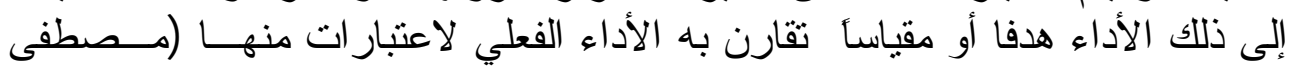

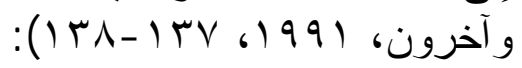

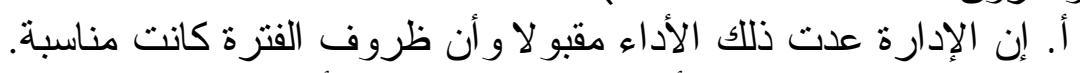

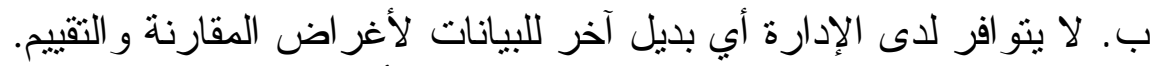

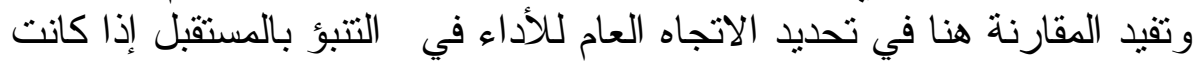
الظروف مستقرة نسبياً.

r. أسلوب المقارنة مع بيانات الأداء الفعلي للوحدات الخدمية المماثلة

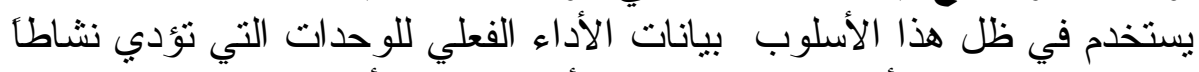

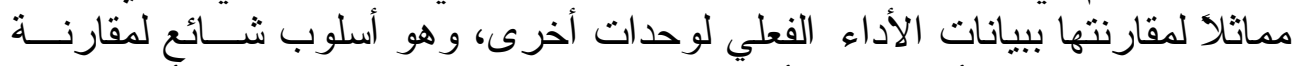

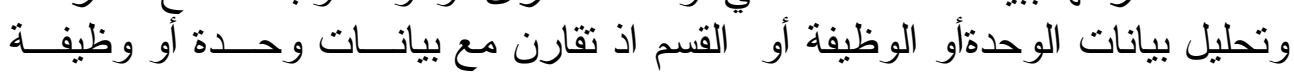


أخرى أو قسم آخر يؤدي نشاطا مشابهاً للنشاط الأول (مصطفى و آخــرون، 9919 (ITN- ITV

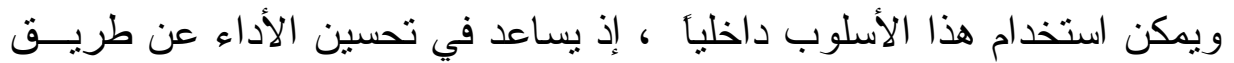

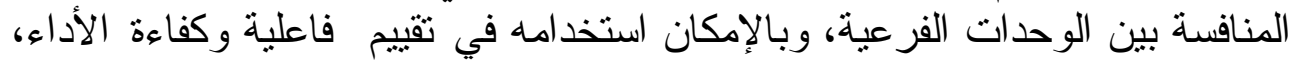

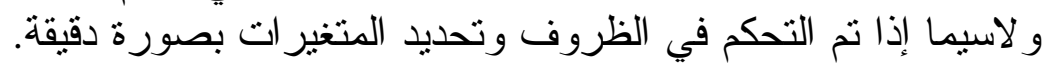

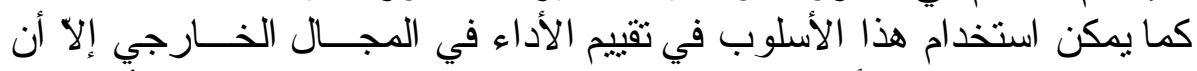

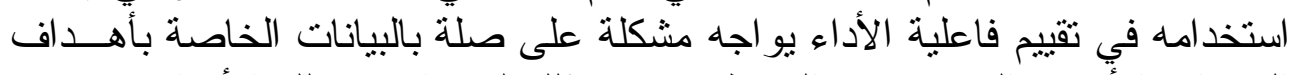

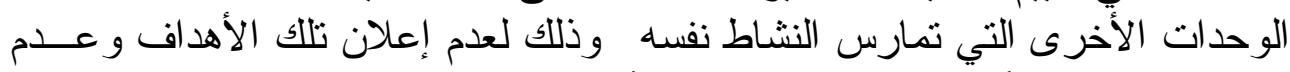

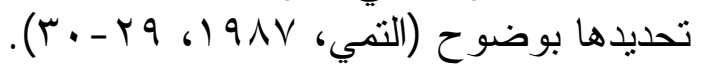

r. أسلوب المقارنة بيانات الأداء المعياري

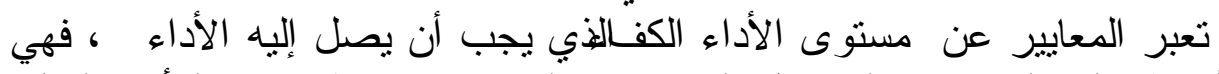

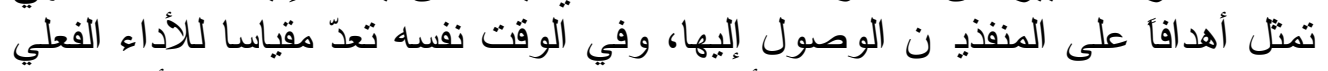

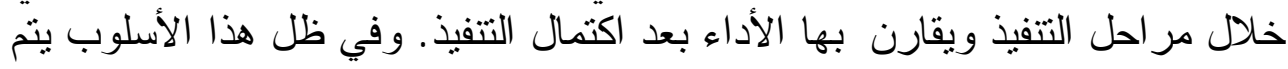

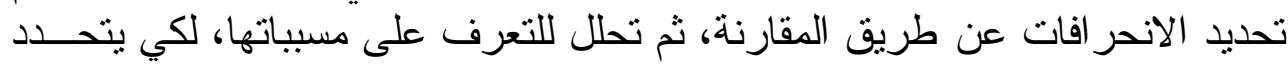

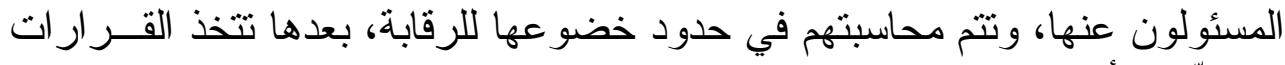
المحسّة للأداء استتادَ الى ذلى فلك.

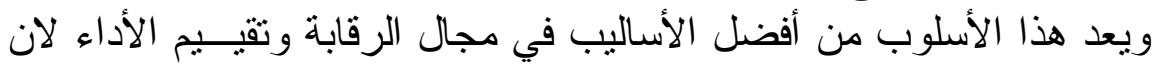

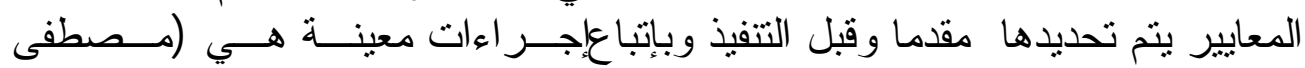

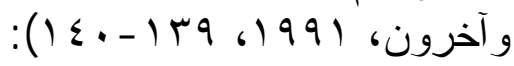

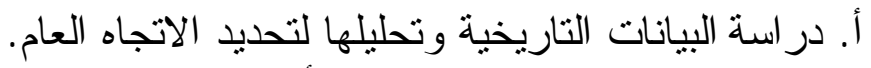
ب. تعديل نتيجة الدر اسات السابقة بالأصول العارية العلمية و الفنية.

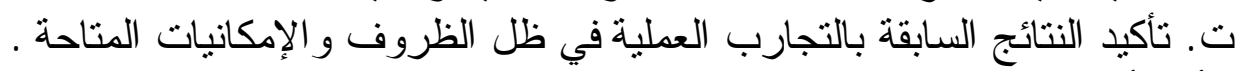

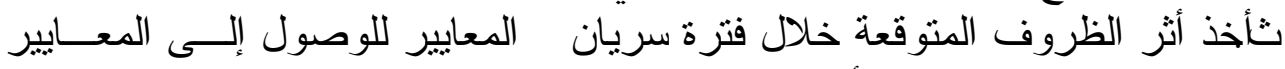

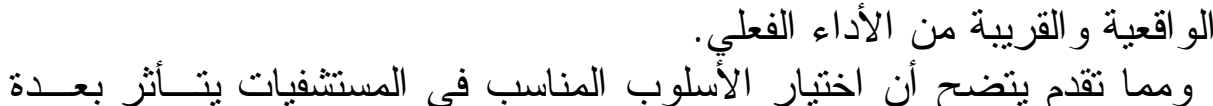

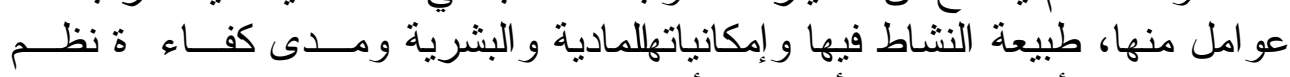

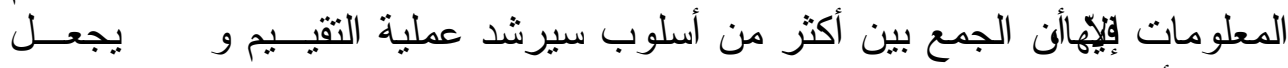
نتائجها أكثر دقة و الكفاءة.

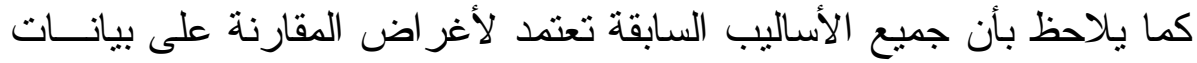

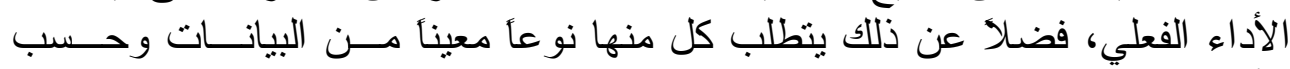

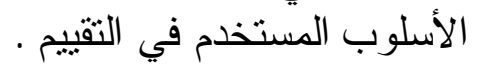

رابعاً - أدوات تقييم الأداء في المستثثفيات الممولة ذاتياً

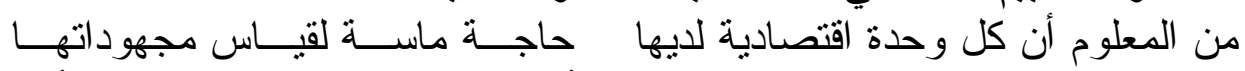

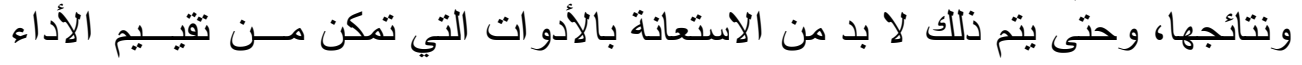




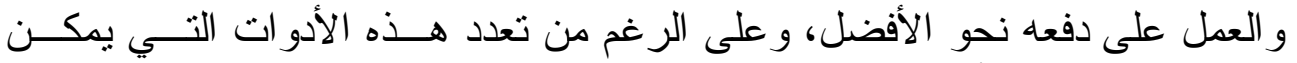

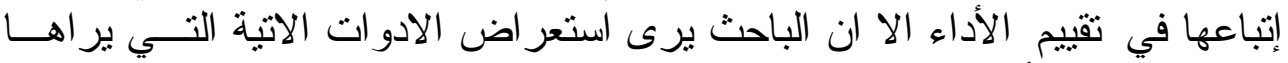

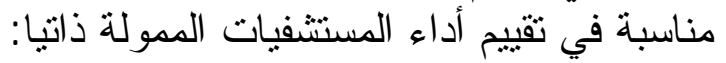
اـ التحليل المالي باستخدام النسب الماءلية.

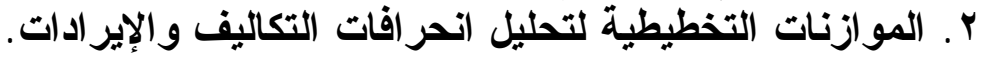
r. تحليل حساسية الربحية في المستشفيات. ء. معايير ومؤشر ات تقييم الأداء في المستشفيلة الريات.

\section{1. التحليل المالي باستخدام النسب المالية}

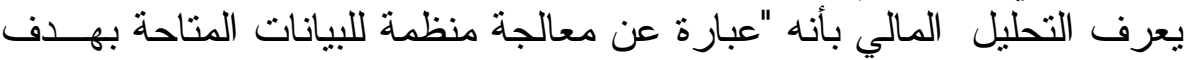

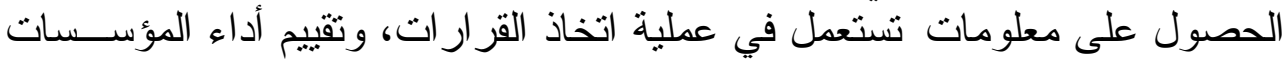

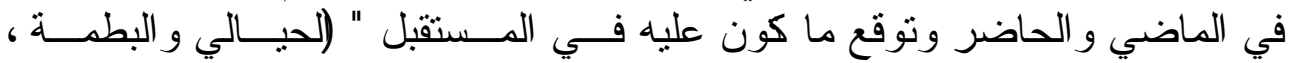
. (r. 6) 1997 كما عرف بأنه "عبارة عن القيام بدر اسة وتحليل الأرقام الناتجة عن العلاقات

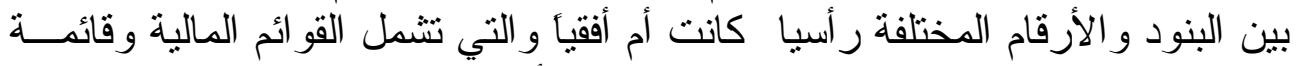

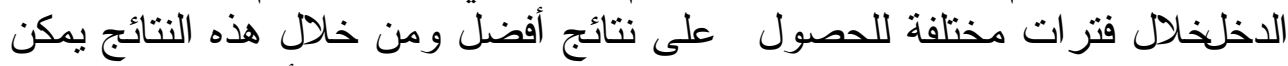

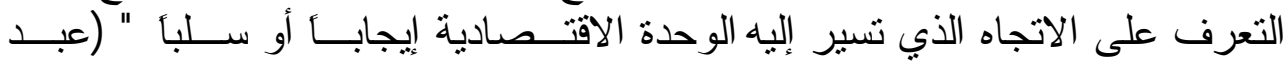

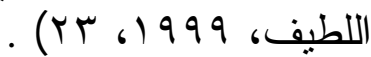

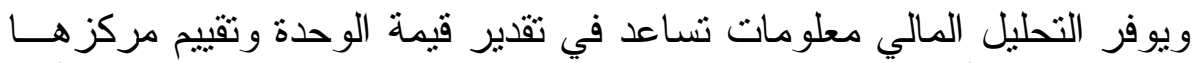
المالي ومدى فاعلية أنشطتها المختلفة وكفاعتها، ويساعد التحليل المالي في تقاعلي تقييم أداء

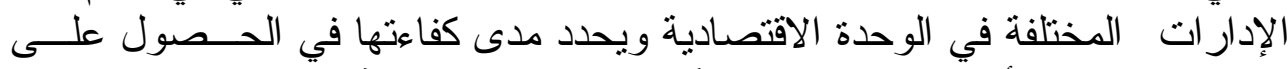

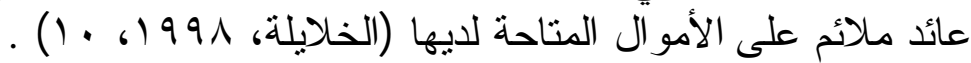

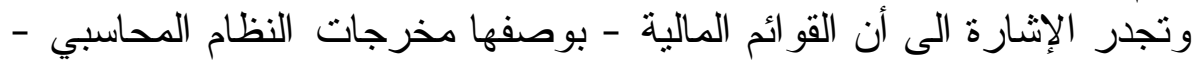

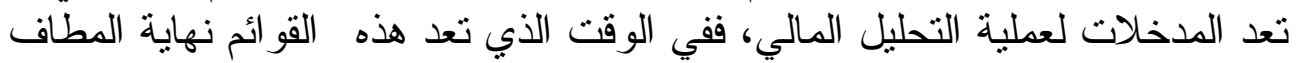

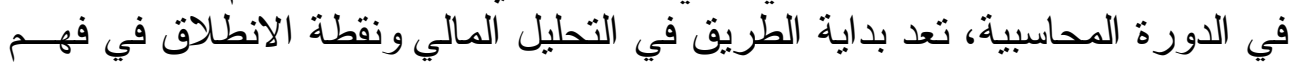

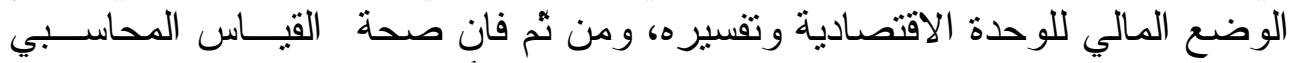

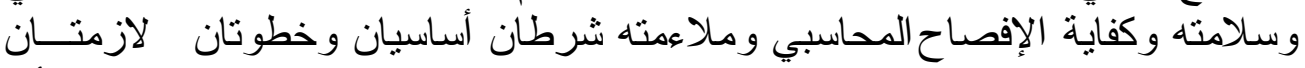

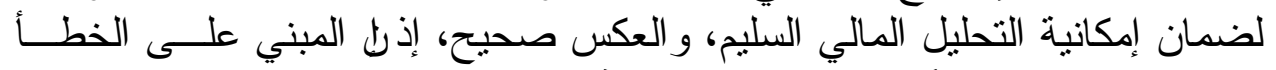

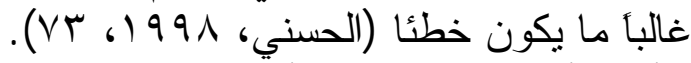

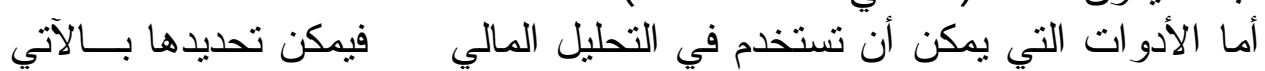

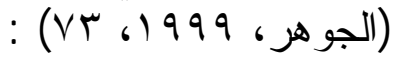
الكقارنات وبيان التغير ات و الاتجاهات ويتم ذلك بمقارنة أرقام سنة مالية بأخرى

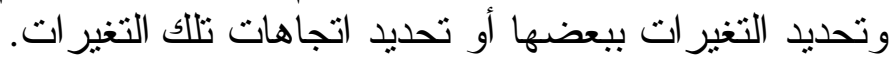

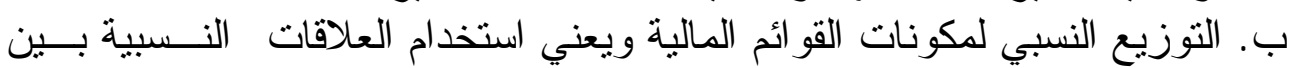

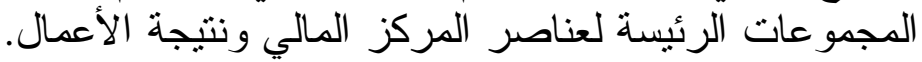

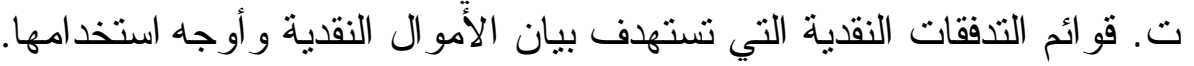


ث. النسب المالية التي تهتم باستخدام العلاقات بين مفردات عناصر المركز المــالي

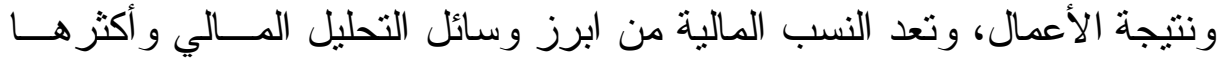

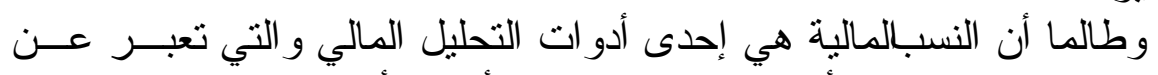
شيو عأ.

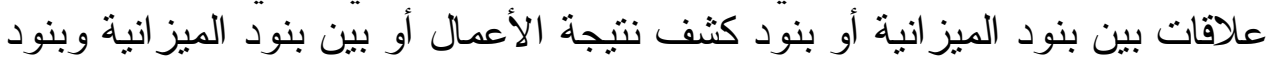

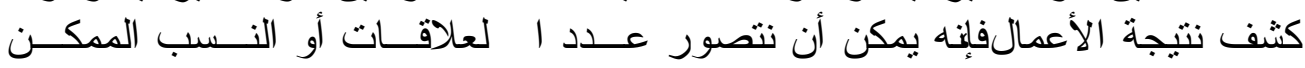

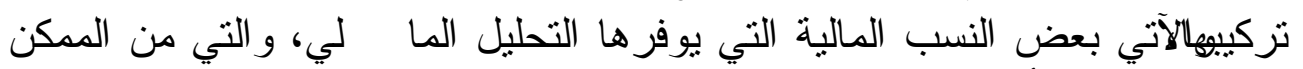

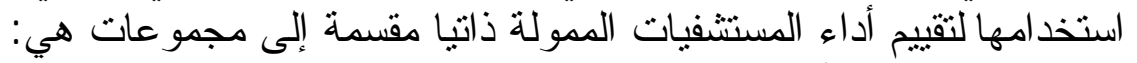

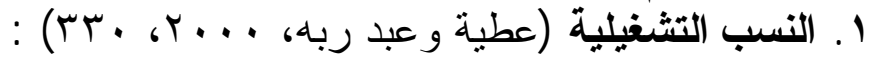

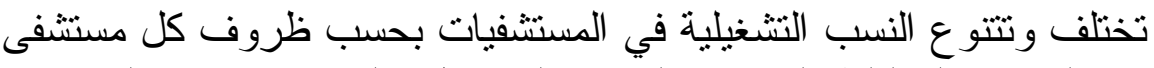

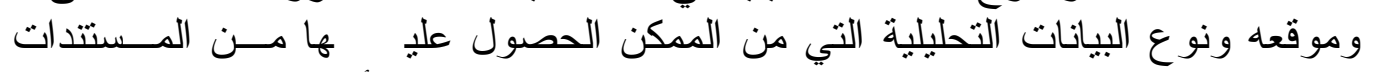

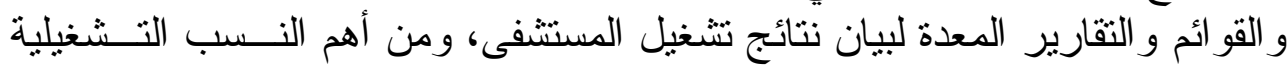

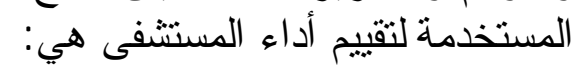

\section{أ.مجموعة نسب ربحية الأشطة العلاجية}

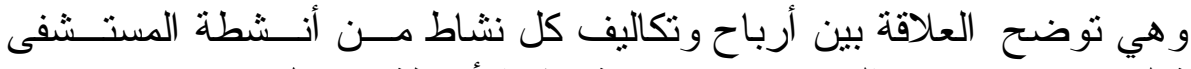
الرئيسة لتحديد مدى كفاءة المسنتفى في تتمية هذه الأنشطة ونتشمل :

$$
\begin{aligned}
& \text { إجمالي اير ادات الإقامة- إجمالي تكاليف الإقامة }
\end{aligned}
$$

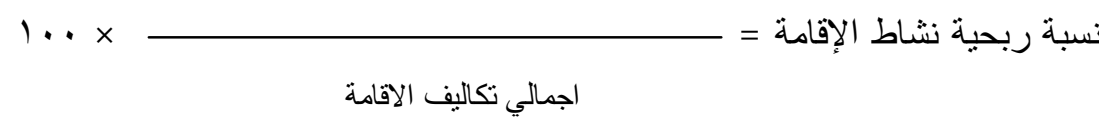

$$
\begin{aligned}
& \text { اجمالي اير ادات العيادات ـ اجمالي تكاليف } \\
& \text { نسبة ربحية نشاط العيادات= }=1 \text { اجمالي تكاليف العيادات }
\end{aligned}
$$

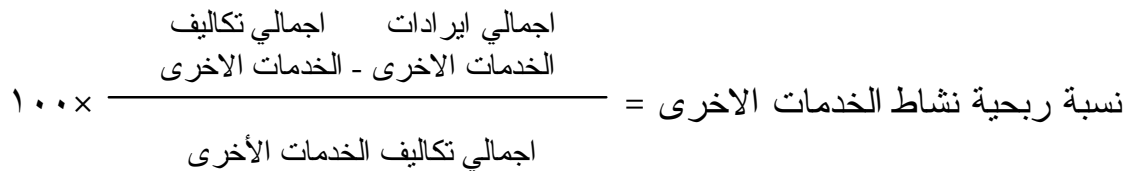

\section{ب ـ مجموعة نسب تكاليف التشغيل المباشرة للمستشفى التشي}

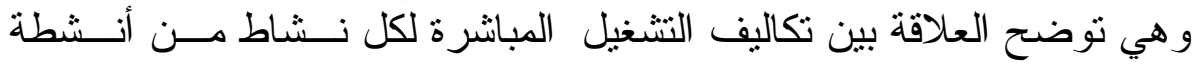

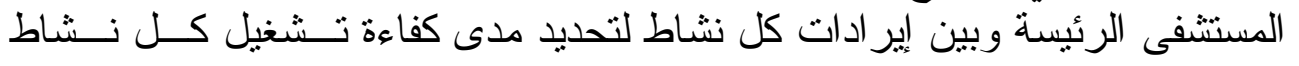


$(r \wedge) \wedge \varepsilon$ [ب] كلية الادارة و الاقتصاد/جامعة الموصل

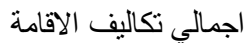

$$
\begin{aligned}
& \text { نسبة تكاليف الاقامة = }=1 \text { اجمالي اير ادات الاقامة }
\end{aligned}
$$

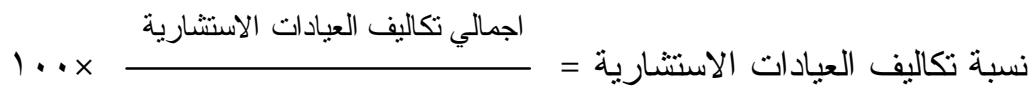

$$
\begin{aligned}
& \text { اجمالي اير ادات العيادات الاستشارية }
\end{aligned}
$$

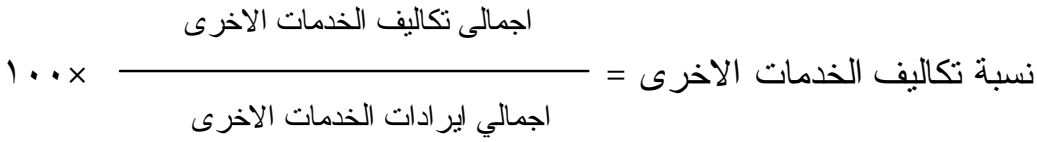

ت. مجموعة نسب تكاليف التشغيل غير المباشرة في المستثفى و هي توضح العلاقة بين تكاليف التشغيل غير المباشرة لكل نشاط من أنـشطة شئة

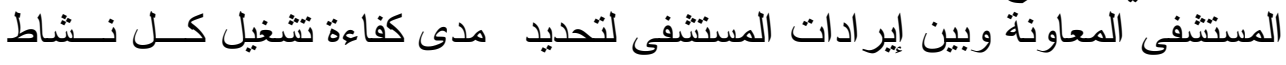
:

$$
\begin{aligned}
& \text { اجمالي التكاليف العمومية و الإدارية } \\
& \text { نسبة التكاليف العمومية و الإدارية= } \\
& \text { اجمالي إير ادات المستشفى } \\
& \text { نسبة التكاليف التسويقية= }=1 \text { اجمالي تكاليف التسويق إير ادات المستشفىى } \\
& \text { نسبة تكاليف الطاقة و الإنارة }=1 \text { × اجمالي إير ادات المستشفى الطاليف و الإنارة } \\
& \text { اجمالي تكاليف الصيانة و الإصلاحات } \\
& \text { نسبة تكاليف الصيانة و الإصلاحات= } \\
& \text { اجمالي إير ادات المستشفى }
\end{aligned}
$$

ث. مجموعة نسب النشاط

هنالك مجموعة من النسب التي يمكن ان تستخدم في قياس قدرة المستـشفيات في استخدام الموارد المتاحة لديها بفاعلية وكفاءة ليثّم ذلك بإجر اء المقارنات بــين 


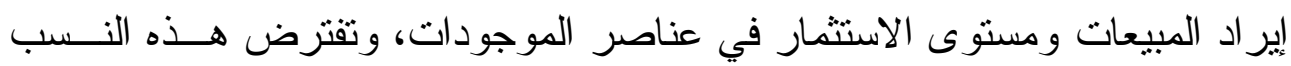

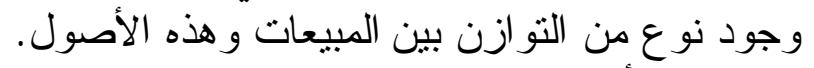

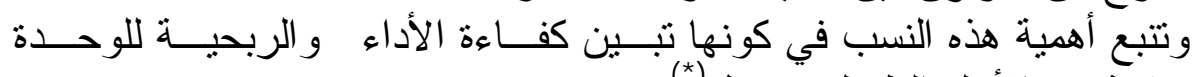

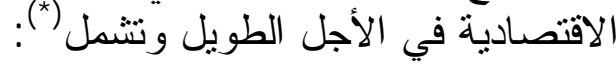

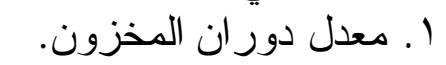

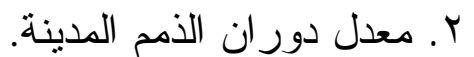
r. معدل دور ان الأصول دورل الثابتة.

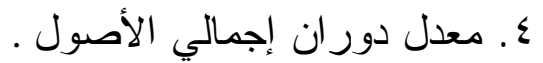

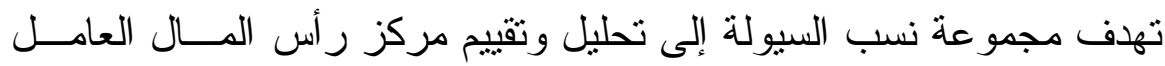

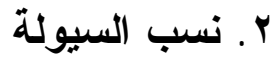
و التعرف على درجة تداول عناصره بهرف الحكم على على مقدرة الوحدة الاقتصادية

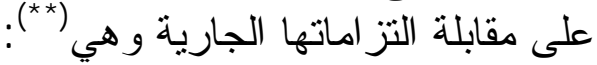

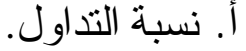
ب. ب. نسبة السيولة السريعة. ت. ت. معدل الفاصل الدفاعي الأساسي.

\section{r. نسب الربحية (مؤشر ات الربحية)}

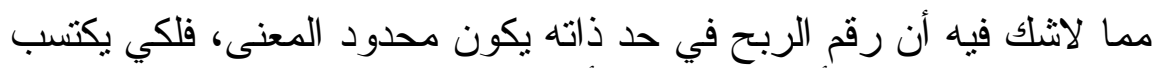

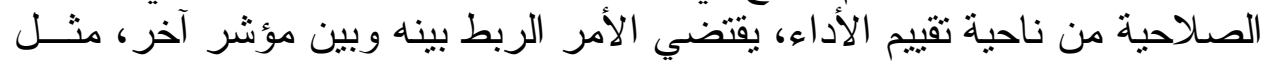

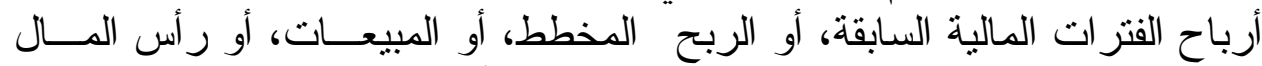

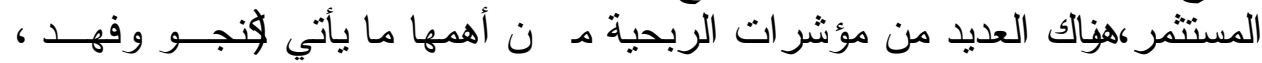

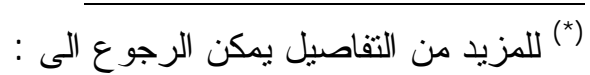

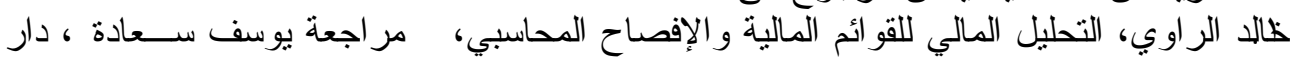

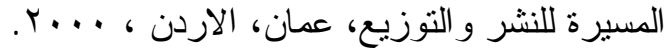

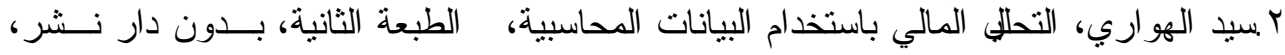

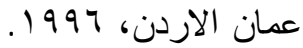

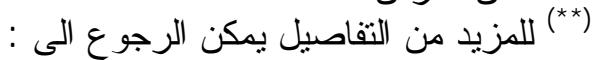
ملحهود عبد الحليم الخلايلة، التحليل الماللي باستخدام البيانات المحاسبية، الطبعة الثانية، بـدون

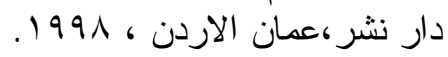




\section{r. الموازنات التخطيطية لتحليل اتحر افات الإير ادات و التكاليف}

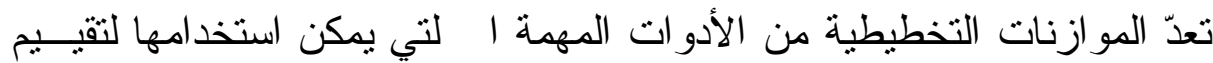

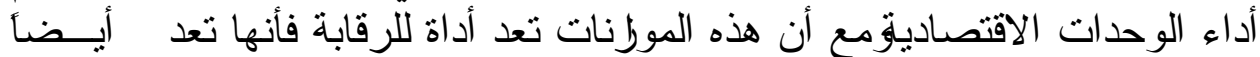

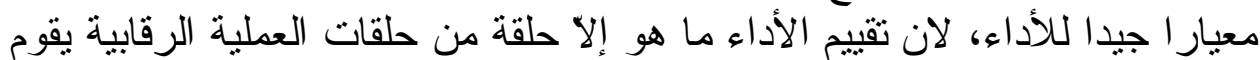

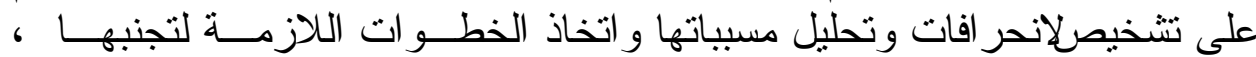
فضلا عن تحديد الجهات المسئولة عنها.

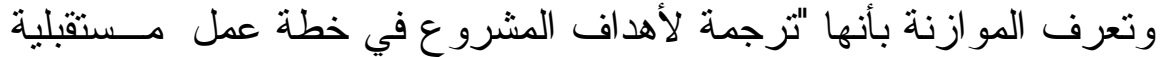

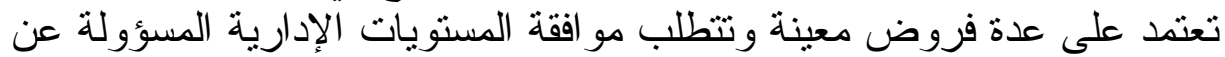

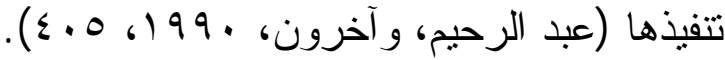

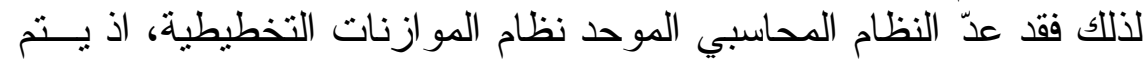

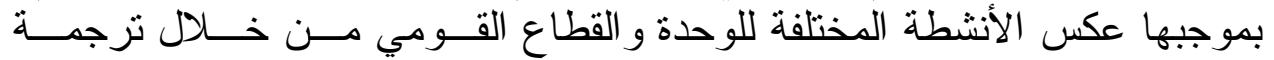
المؤشر ات الكمية و الخطط النوعية لتنفيذ السياسات وتحقيق الأهداف إلى موازنات التهات

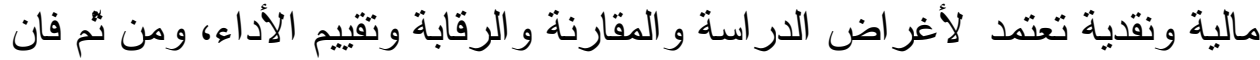

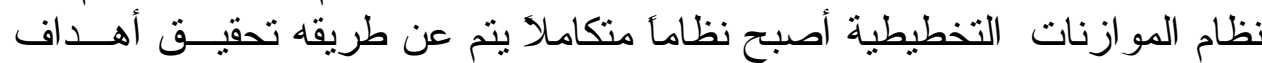

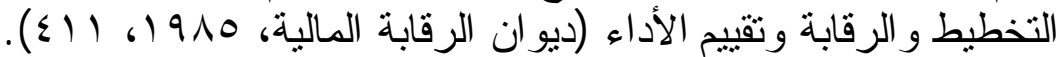

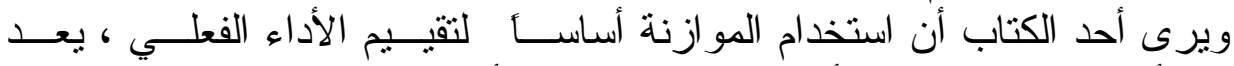

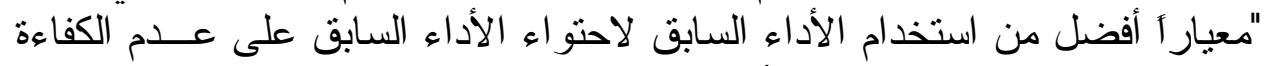

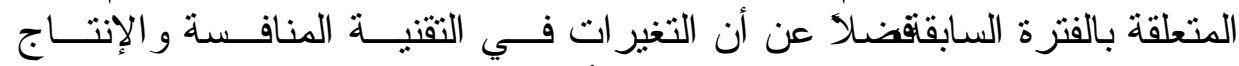

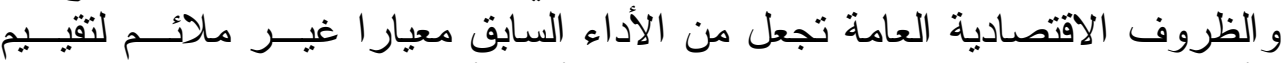

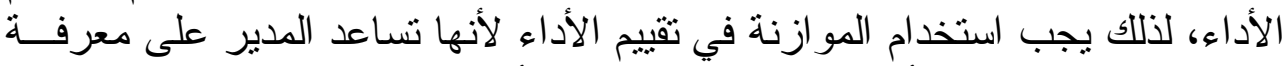

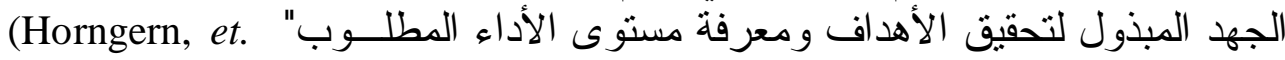

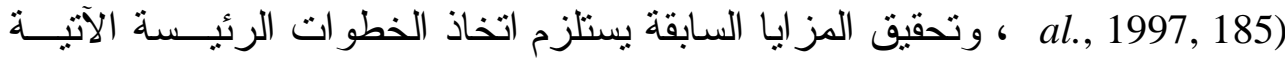

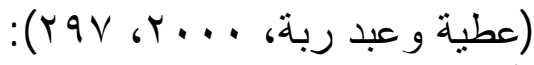

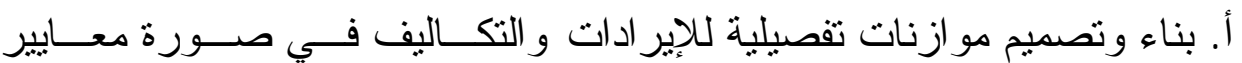

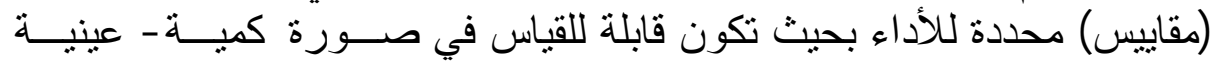

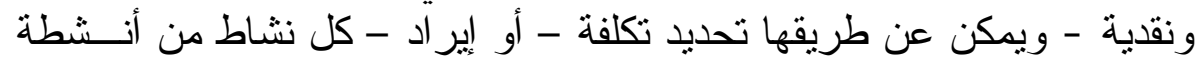
المستشفى .

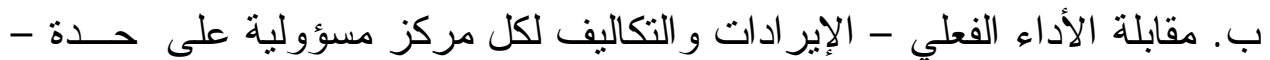

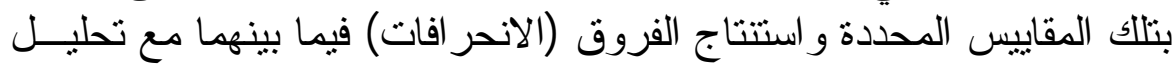
وتقسير عو امل ومسببات ثللك الفروق.

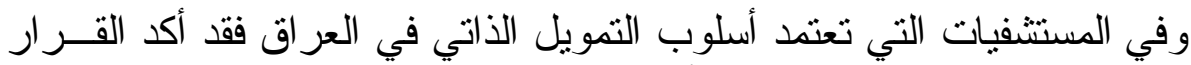

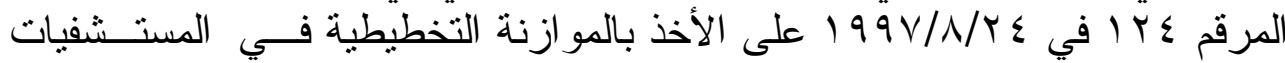

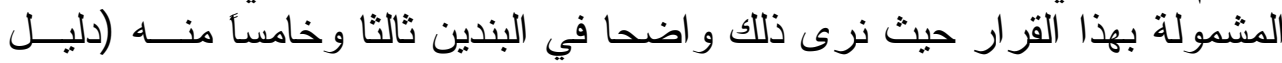

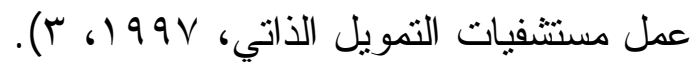

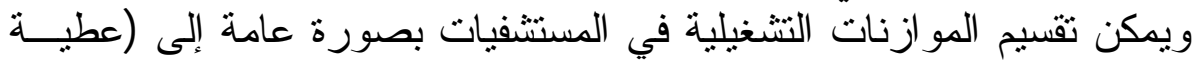
و عبد ربه، ... 
ارديني [ب [ب]

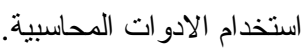

$$
\begin{aligned}
& \text { أ. مو ازنات الإير ادات وتشمل : } \\
& \text { - مو ازنة إير ادات الإقامة. }
\end{aligned}
$$

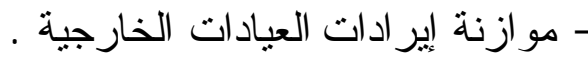

$$
\begin{aligned}
& \text { - مو ازنة إير ادات الخدمات العلاجية الأخرى. }
\end{aligned}
$$

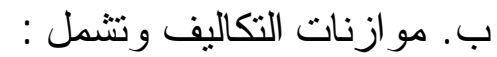

$$
\begin{aligned}
& \text { • مو ازنات التكاليف المباثرة ونتشمل : }
\end{aligned}
$$

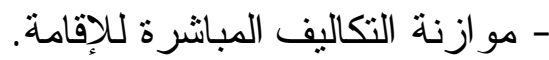

$$
\begin{aligned}
& \text { - مو ازنة التكاليف المباشرة للعيادات الخارجية. }
\end{aligned}
$$

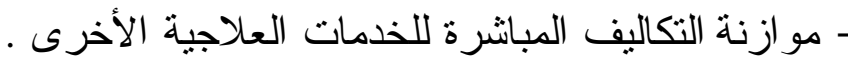

$$
\begin{aligned}
& \text { • موازنة التكاليف غير المباشرة ونتمل : } \\
& \text { - مو ازنة التكاليف الإدارية و العمومية } \\
& \text { - مو ازنة تكاليف الوقود و القوى المحركة. }
\end{aligned}
$$

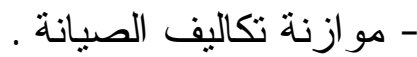

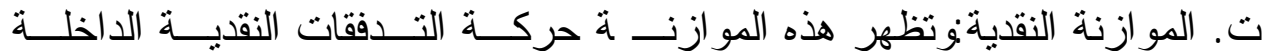

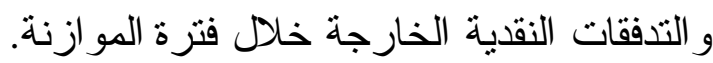

r. تحليل حساسية الربحية في المستشفيات يعدّ أسلوب تحليل حساسية الربحية من الأساليب حديثة الظهور نسبياً، إلأن أن

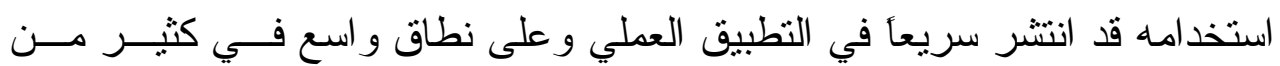

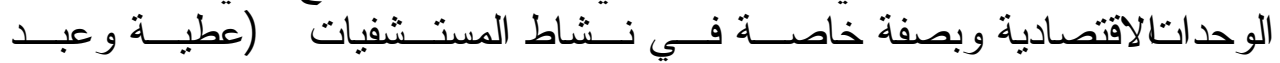

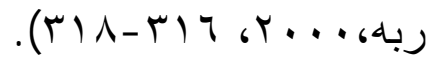

ويعتمد هذا الأسلوب على تحديد أو ق فياس مدى تأثير بعض العو امل المتحكمة

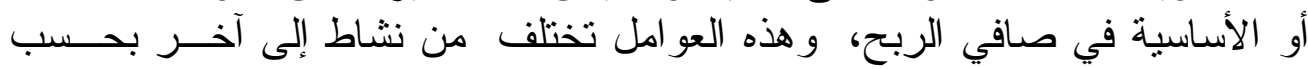

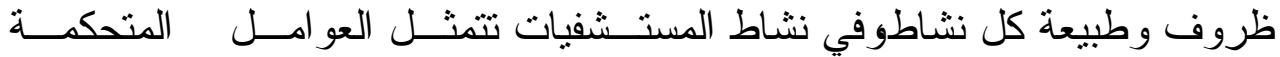

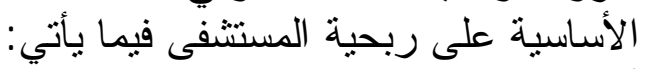

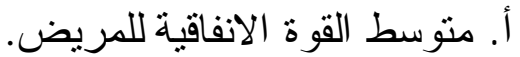
ب. ب. معدل إثنغال السرير. ت. أسعار بيع الخدمات العلاجية المختلفة (إقامة، عيادات خارجية، أنتعة وتحليـل،

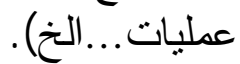

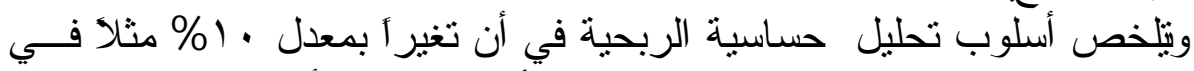

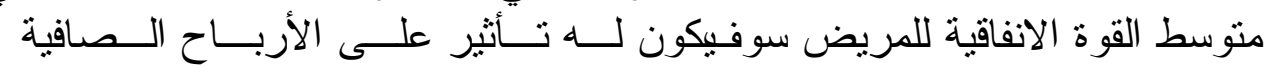

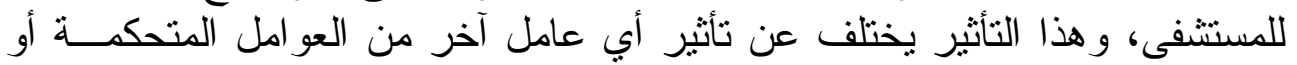

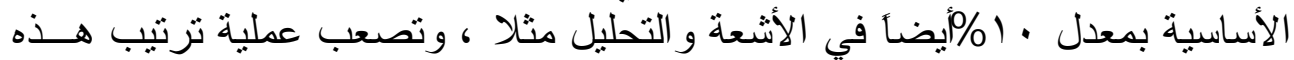

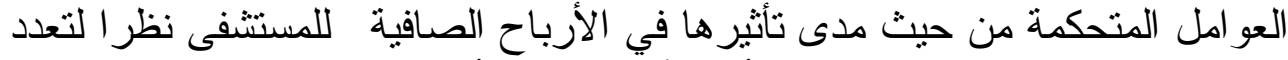

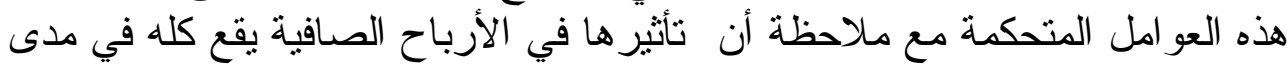

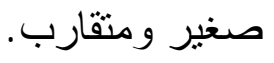


أما الخطو ات الأساسية لتحليل حساسية الربحية فتمنل بالآتي:

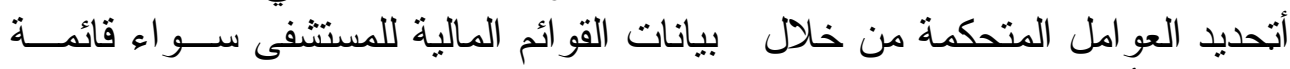

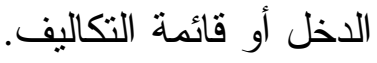

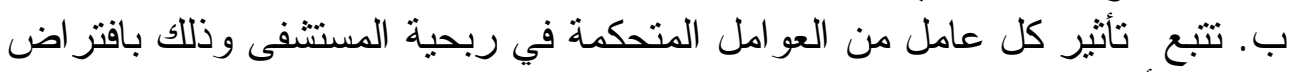

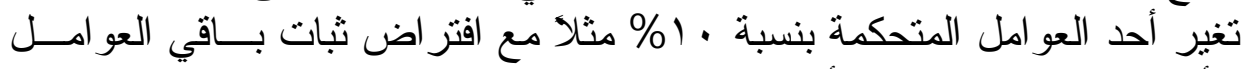

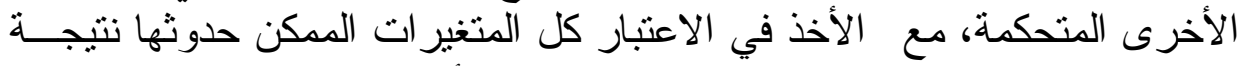

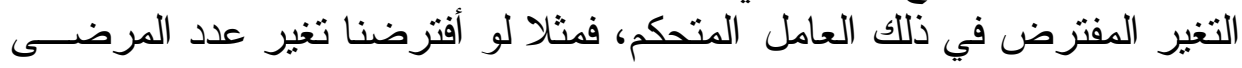

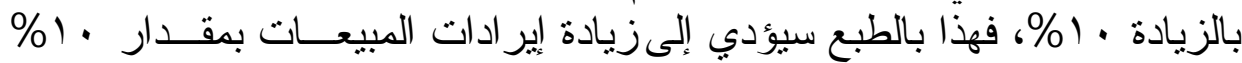

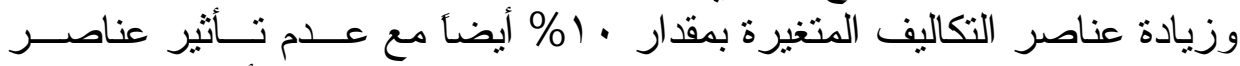

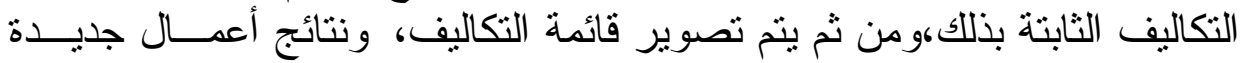

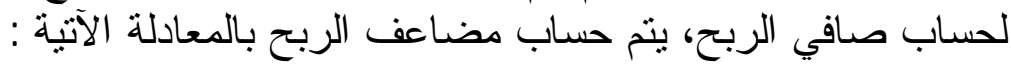

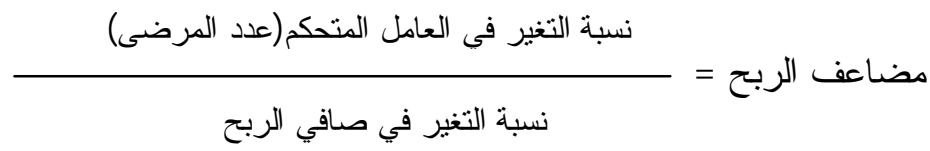

ت. ترتيب العو امل المتحكمة بحسب أهميتها وذللك من خلال إعادة الخطوة الــسابقة

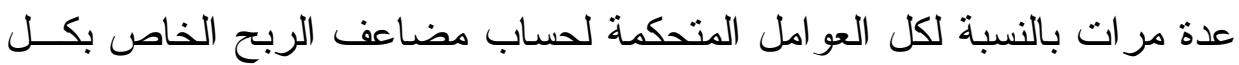

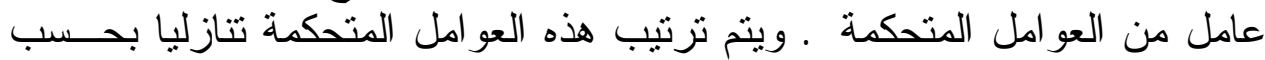

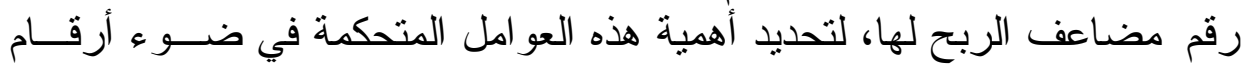

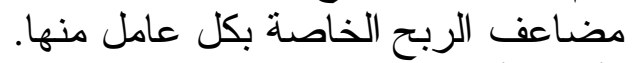

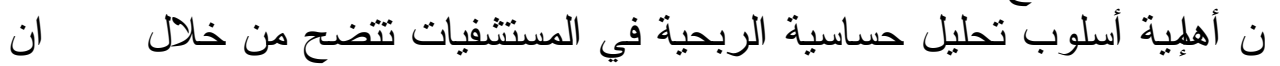

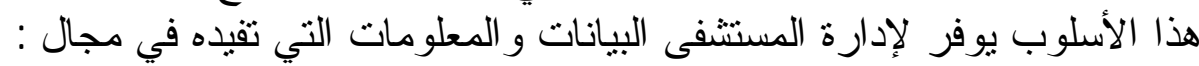

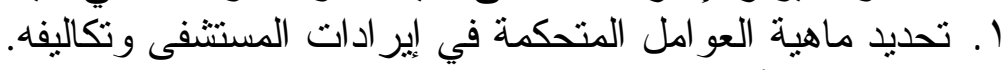
r. تحديد مدى تأثير كل عامل من العو امل المتحكمة في ربحية المبية المستشفى.

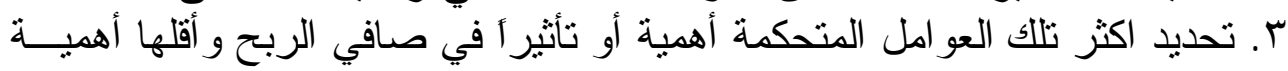

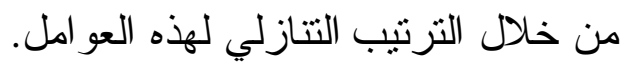

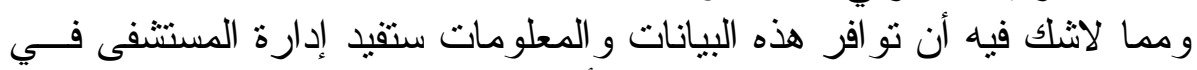
رسم وتوجيه مختلف سياسات المستشفى على أسس سليمة ألى أنسات

\section{ع ـ معايير ومؤشرات تقييم الأداء في المستشفيات}

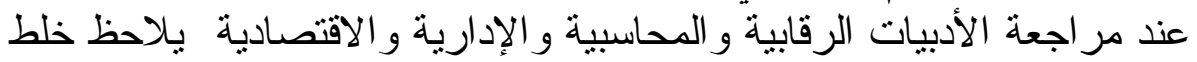

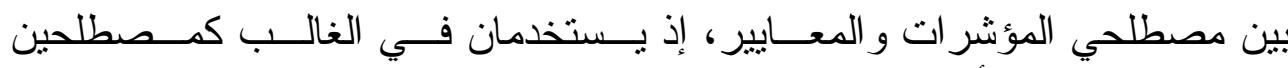

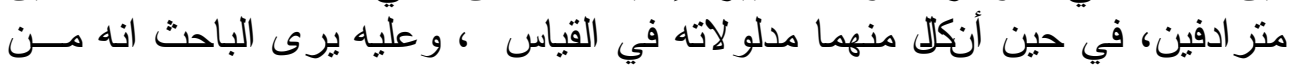
المناسب تحديد مفهوم هذين المصنئ فين الحين. فقد عرف المعيار بأنكلل ما يستخدم في القياس فقد يكون إنموذجا أو مثالا

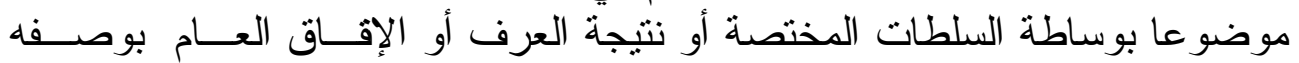


ارديني [بر

أساسأ لما يجب اتباعه وقد يتمنت في أحد الأشكال الآتية، وزن، حجـــه، محتويــات

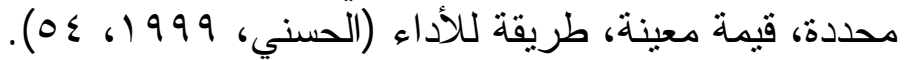

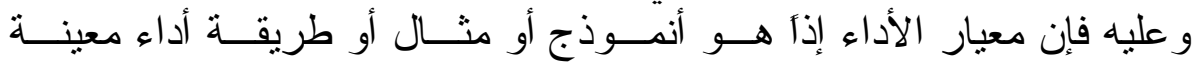

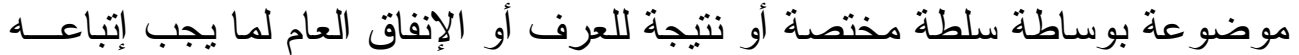

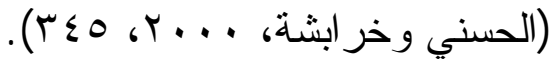

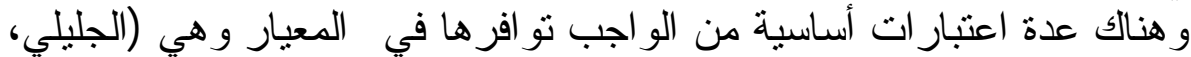
$:(Y 7,6) 9 V V$

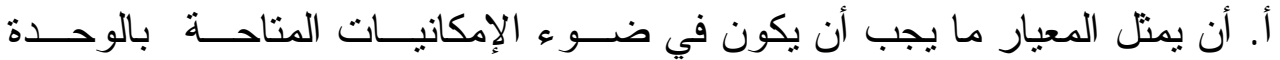
الاقتصادية. ب. أن يكون المعيار مقبو لا من المنفذين.

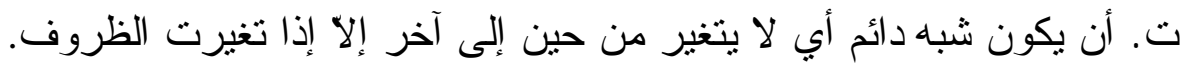

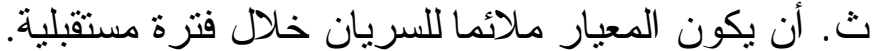

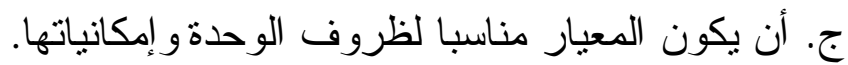

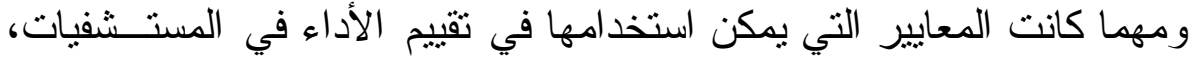

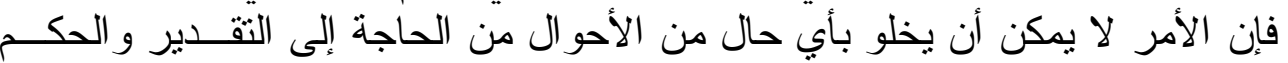

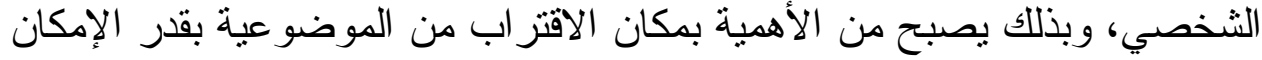

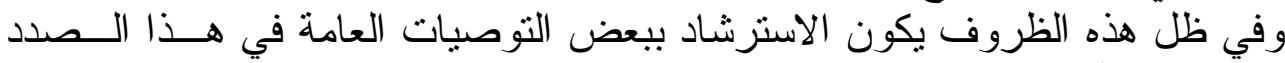

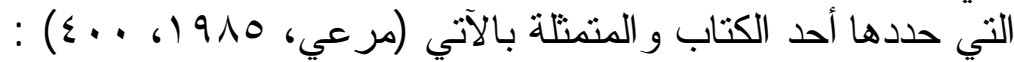

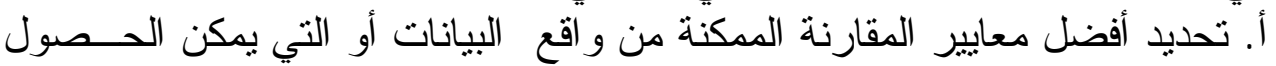
عليها بتكلفة معقولة في ظل الظريد الظروف المحيطة.

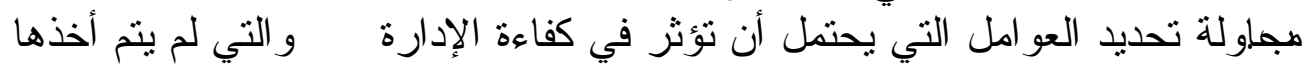

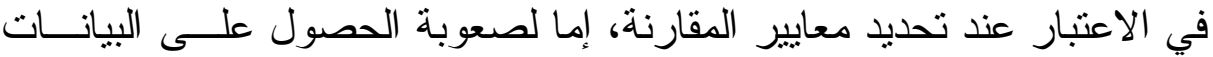

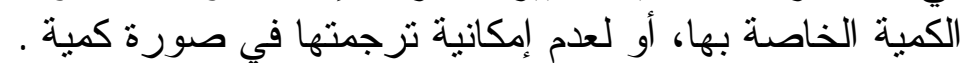

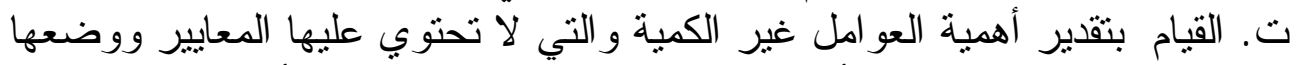

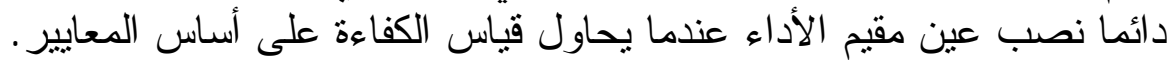

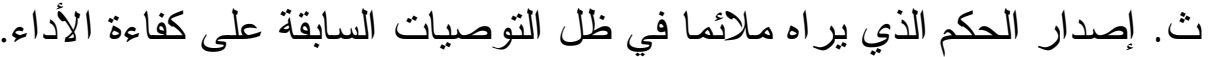

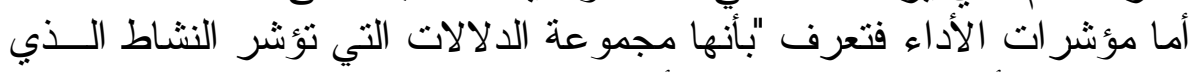

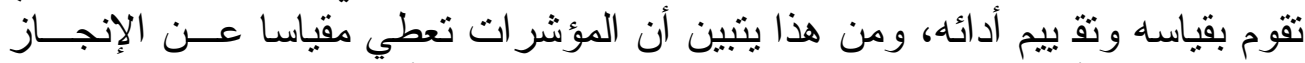

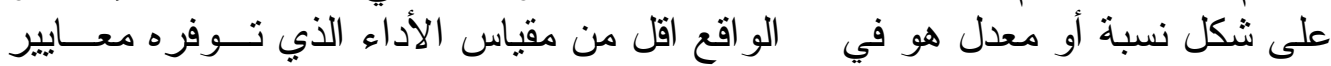

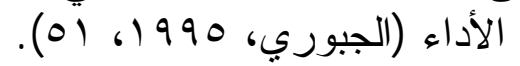

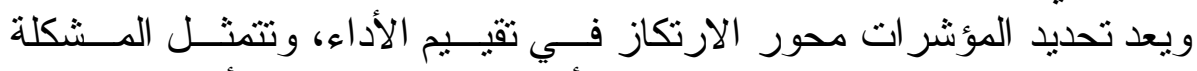

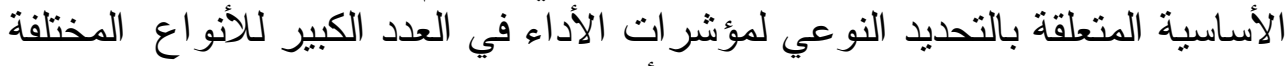

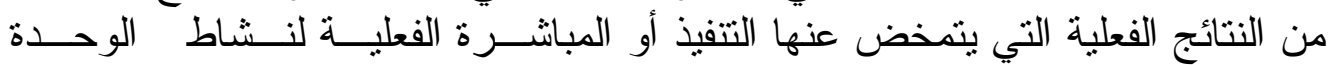

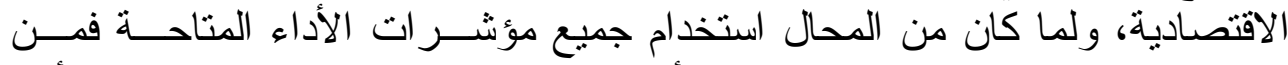

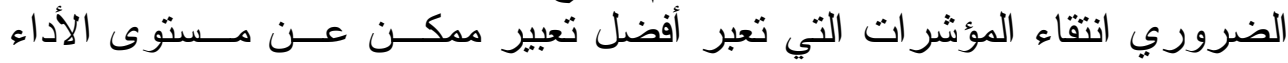

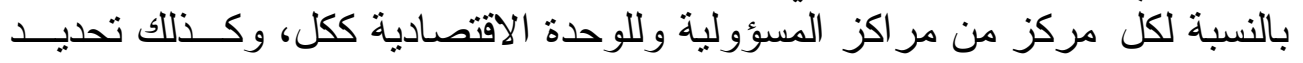




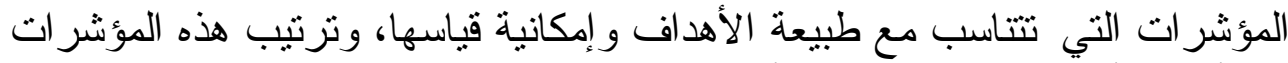

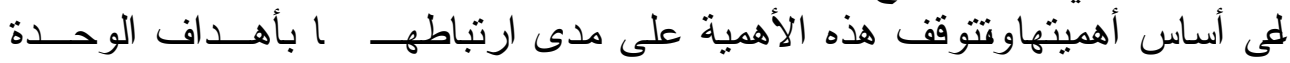

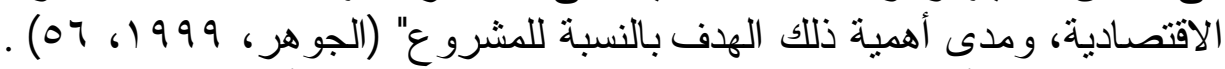

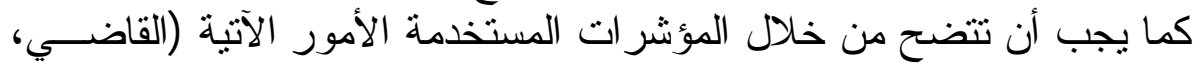
$:(\leqslant 0$ ) 6997

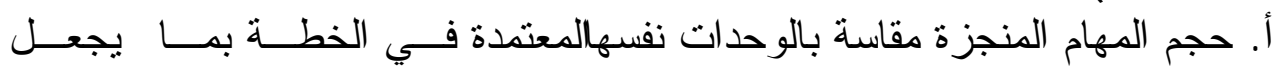

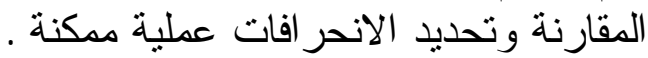

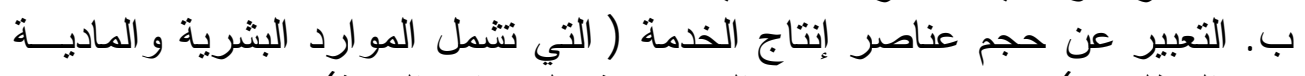

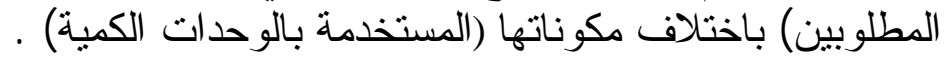

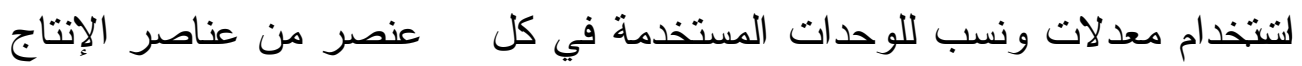
اللازمة لإنجاز الخدمات . لإت التات

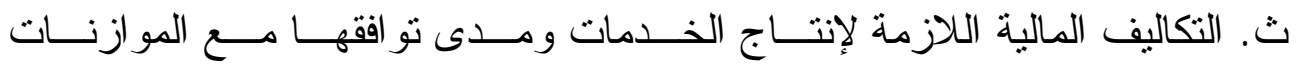
التخطبطية.

ج. الوقت المستغرق لأداء الخدمة مقارنة بالوقت المعياري المعتمد في الخطة.

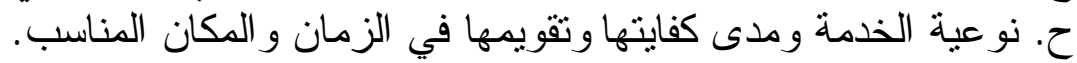
د. درجة رضا المستقيدين من الخدمة ومنة

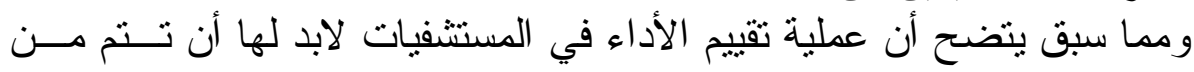

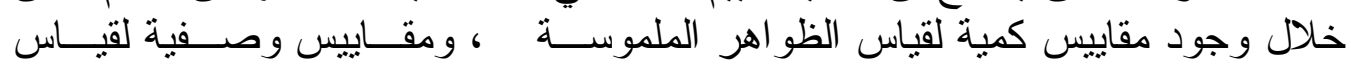

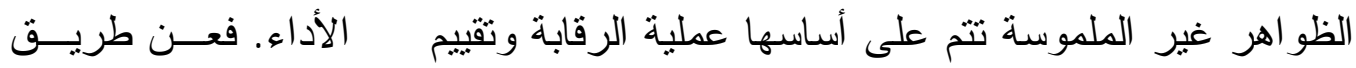

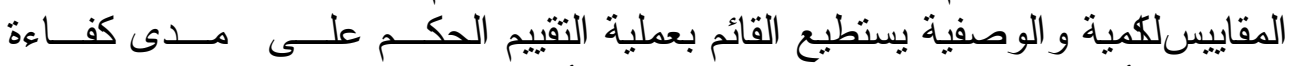

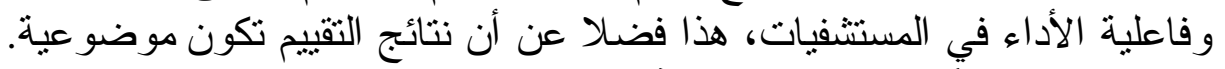

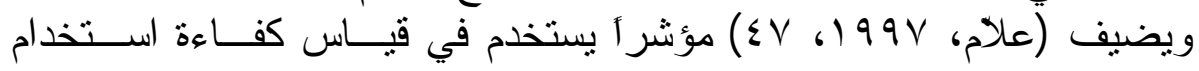

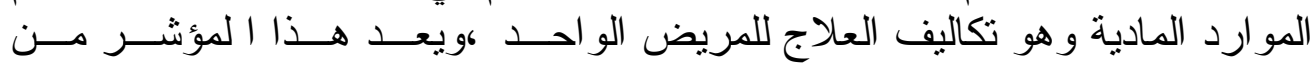

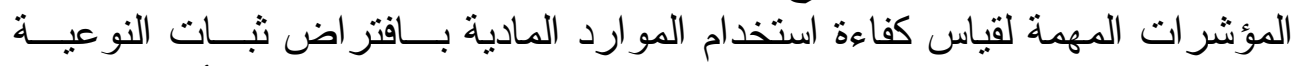

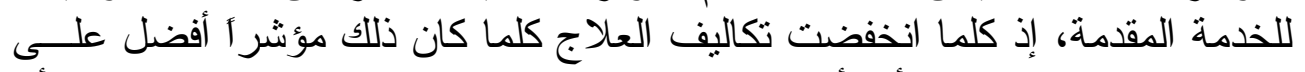

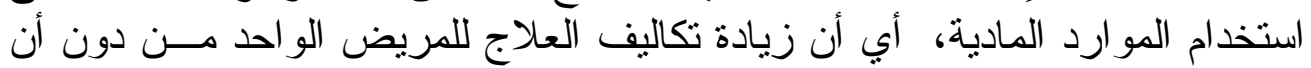

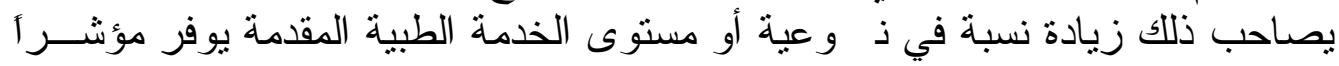

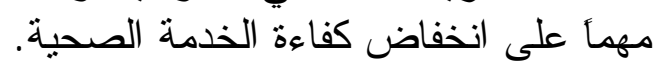
ويمكن إخضاع الخدمات الصحية للقياس التكاليفي، وذللك من خــلال الآتـي :(Ali, 1976, 196) أ. قياس تكلفة مرضى الإقامة

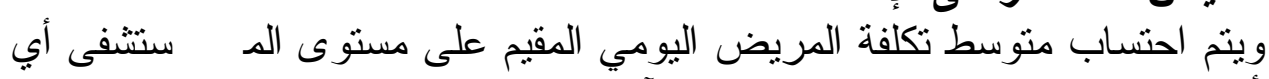

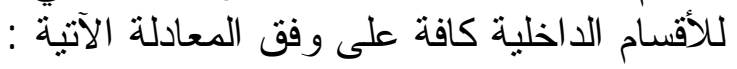

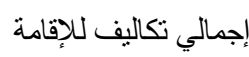




\section{ب. قياس تكلفة مرضى العيادات الاستثارية}

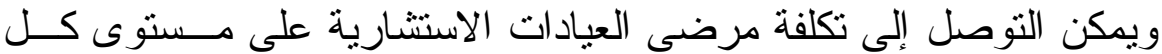

العيادات الاستشارية باستخدام المعادلات الآتية :

الكلفة الكلية لجميع العيادات الاستشارية

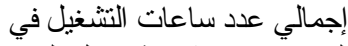

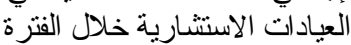

متوسط تكلفة ساعة التشغيل للعيادات الاستشارية متوسط تكلفة الكثف الو احد في العيادات الاستشارية= متوسط عدد المرتادين على العيادات الاستثارية في الساعة

فضلا عما سبق فان هناك مؤشر ات مالية أخرى يمكن استخدامها فــي تقيــيم

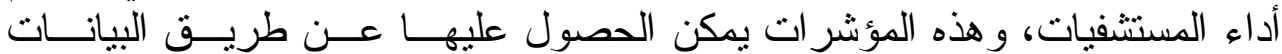

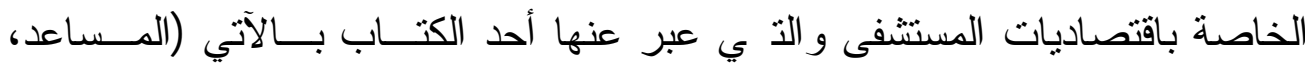
: (V7 6) 991 أ. بيانات بالمصروفات الدورية للمستشفى عموما ولكل قسم من أقسامها .

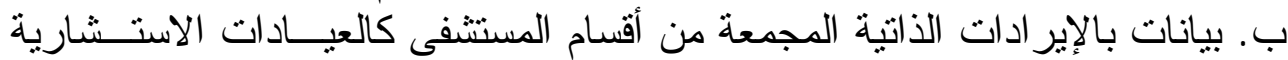

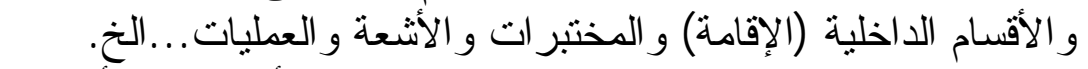
ت. بيانات بالإير ادات عن الإعانات المقدمة من الدولة وأية الإلة إعانات أخرى.

الخلاصة خلص البحث إلى مجموعة من الاستتناجات هي:

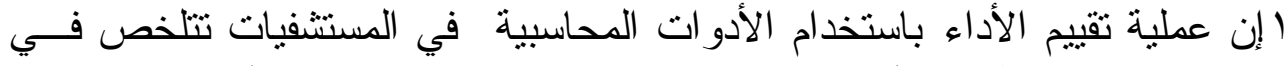

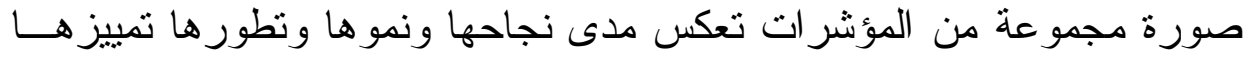

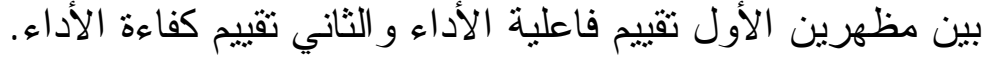

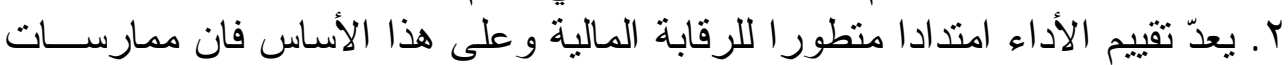

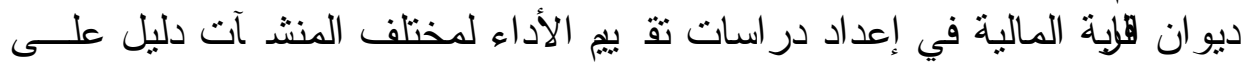
هذا الاستتناج.

r. إن الموازنات التخطيطية نظام منكامل يصلح بوصفه أداة للرقابة وتقييم الأداء. ع. إن إعداد قائمة التدفقات النقدية يسهم في تقييم أداء الوحدة و التدفقات النقدية فيها.

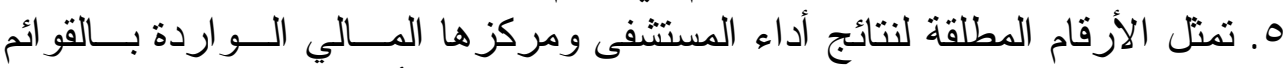

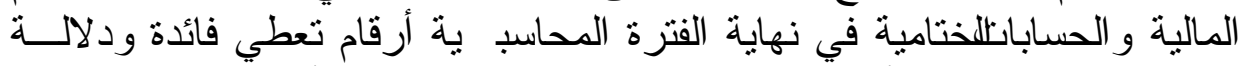

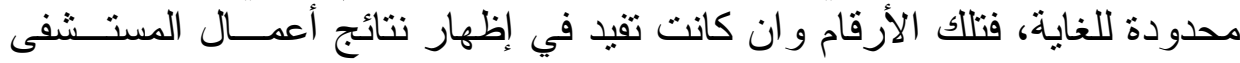

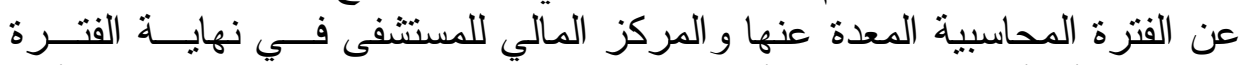

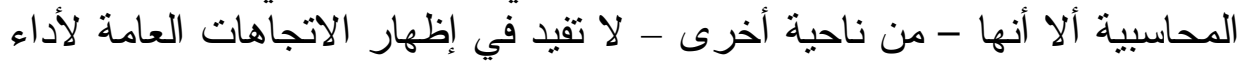

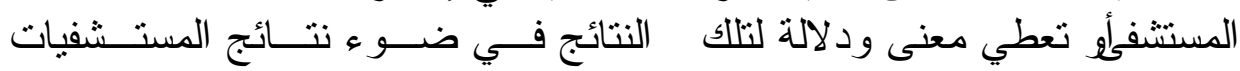




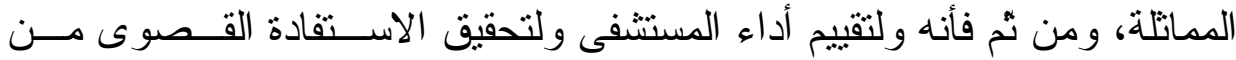

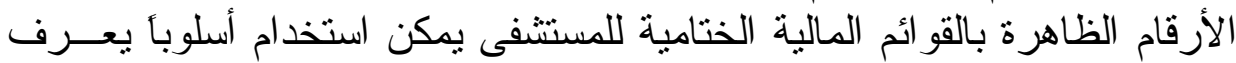
بالتحليل المالي باستخدام النسب المالية .

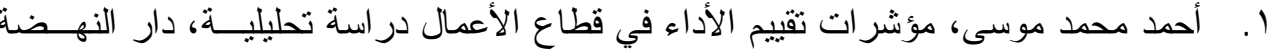

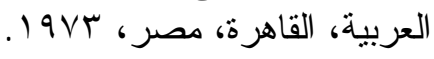

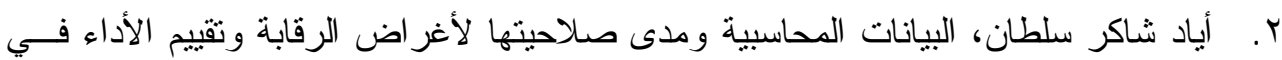

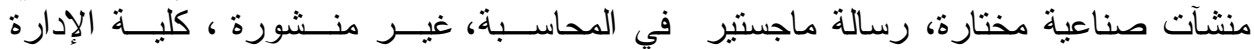

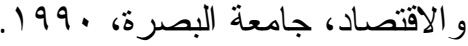

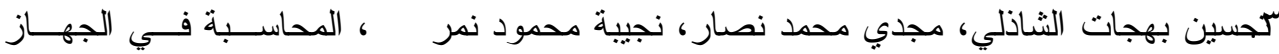

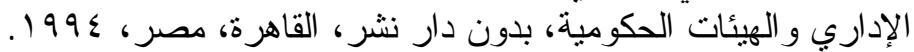

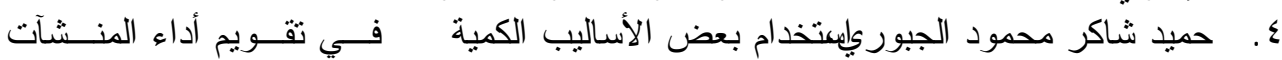

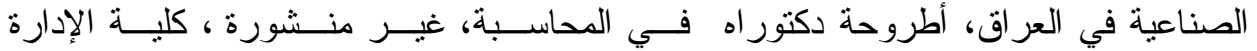

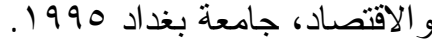

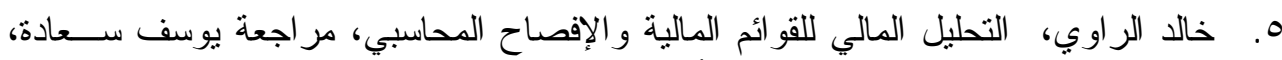

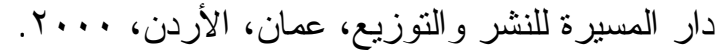

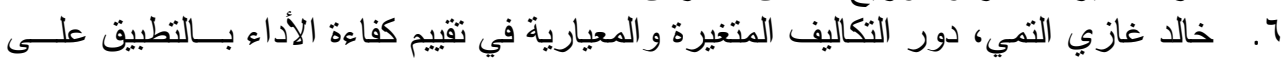

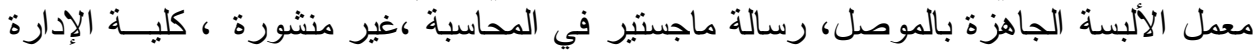

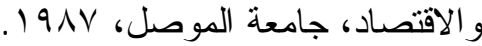

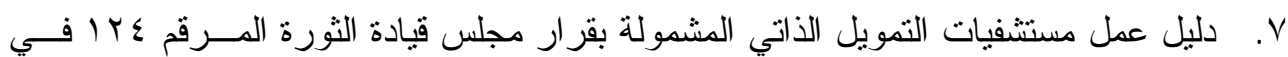
. $199 \mathrm{~V} / \mathrm{N} / \mathrm{K} \leq$

^. ديوان الرقابة المالية ، النظام المحاسبي الموحد، الطبعة الأولى، الـــار العربيــة للطباعــة،

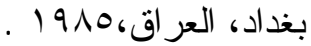

9 9. زكي خليل المساعد، تسويق الخدمات الصحية، دار مكتبة الحامد للنشر و التوزيع، عمــان -

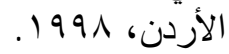
• 1. سيدوالهي، الإدارة المالية منهج اتخاذ قرارات، ط ج، مكتبة عين شمس للتوزيع، القاهرة،

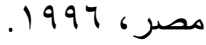

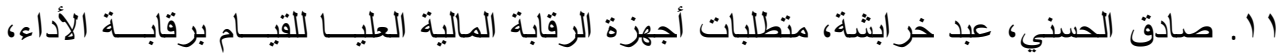

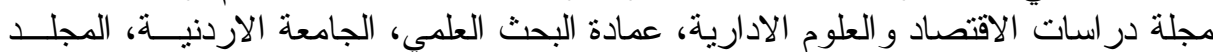

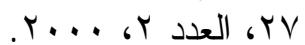

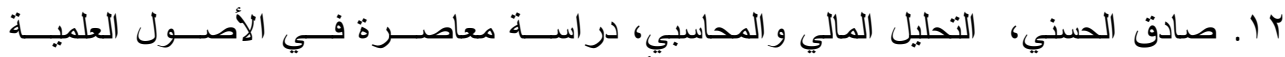

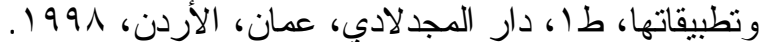

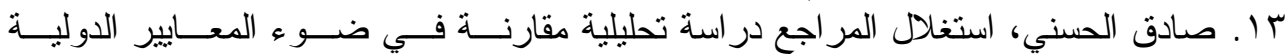

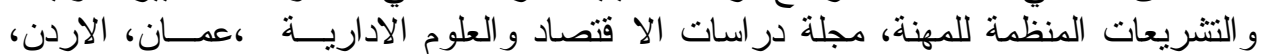

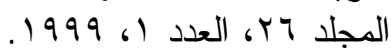

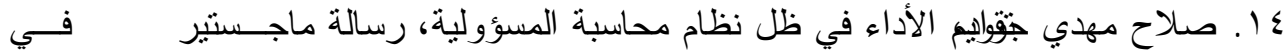

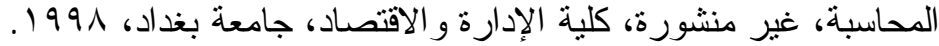

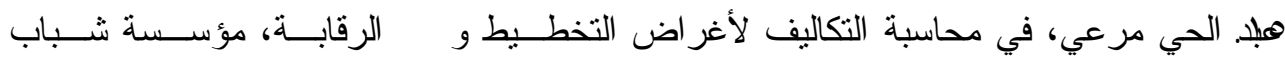




$$
\begin{aligned}
& \text { الجامعة، الاسكندرية، مصر ، } 1910 . \\
& 17
\end{aligned}
$$

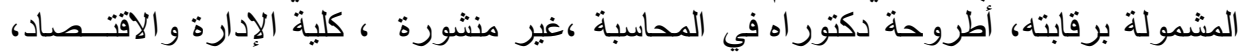

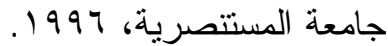

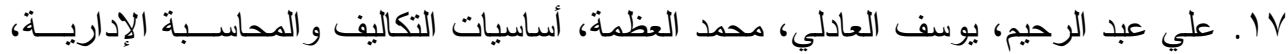

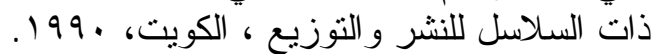

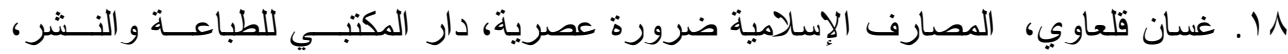

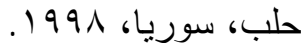

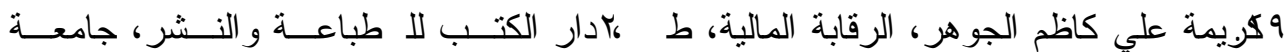

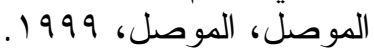

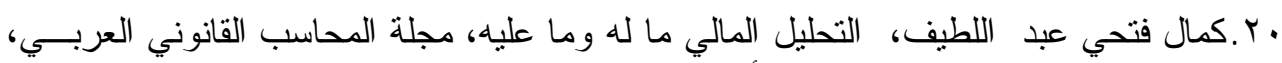

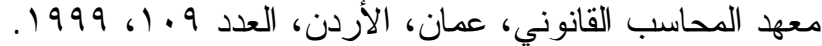

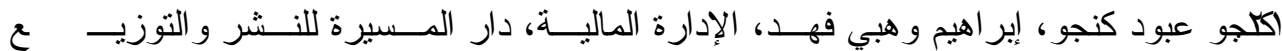

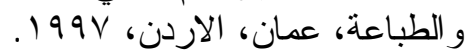

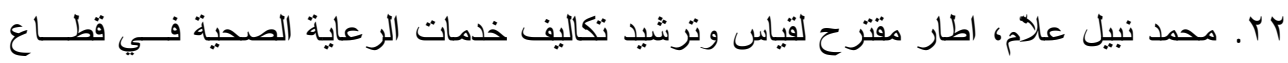

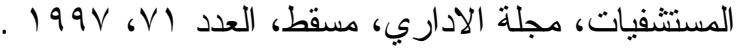

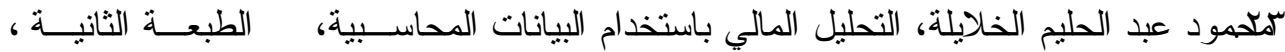

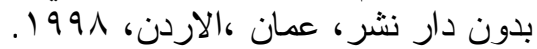

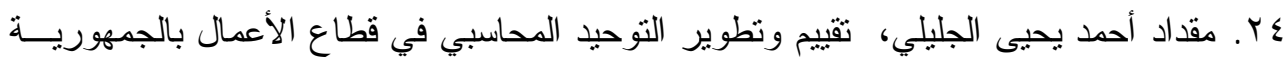

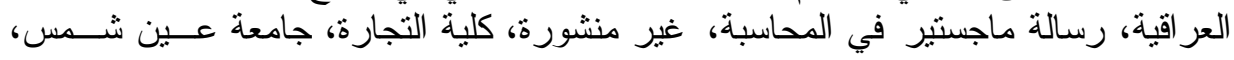

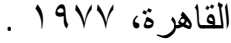

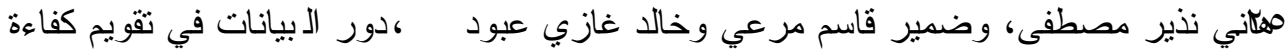

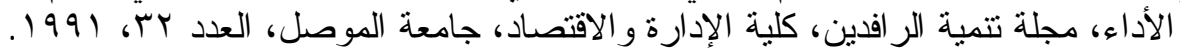

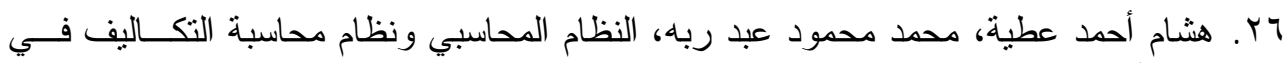

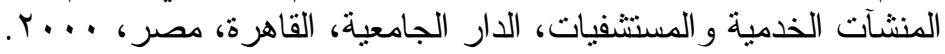

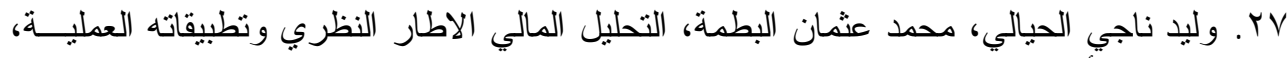

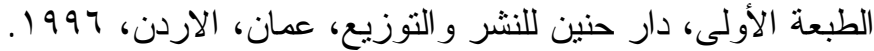

\section{ثانياً - المر اجع باللغة الأجنبية}

1. Horngren, C. T. and George Faster, Cost Accounting: Managerial Emphasis, Ninth Edition, Prentice - Hall, New Jersey, 1997.

2. Ali, Hussein Zunnun, Hastane Isletmleei Yonetiminde Temel Biligiger Ankara, 1976. 